$N^{o} 18,2007$

\title{
Petroglifos y relieves en templos, conventos y Casonas del Cusco
}

\author{
Germán Zecenarro Benavente*
}

\begin{abstract}
Resumen
En ciertas edificaciones levantadas a partir del Siglo XVI, existen piedras de origen prehispánico que presentan sobre sus superficies enigmáticas incisiones y relieves de diseño particular; elementos pertenecientes al mundo religioso y ritual andino. En Cusco quedan muchos e importantes vestigios de este tipo de expresión cultural que, por su relación con determinados espacios urbanos, tipologías arquitectónicas virreinales o antiguos contextos sagrados Inkas, se les pueden atribuir contenidos mágico religiosos que han trascendido y perdurado en el tiempo junto con la arquitectura occidental implantada, confirmándose la continuidad de las entidades sagradas andinas.
\end{abstract}

Palabras clave

Petroglifos, wakas, monolitos, litoescultura, litograbados, Cusco, Inkas, ideografías.

\begin{abstract}
In some edifications lifted up starting from the XVI Century, there are ancient stones that show on their surfaces enigmatic incisions, elements that belong to the religious and ritual Andean World. There are many important traces of these cultural expressions in Cusco than, by their relation with particular urban spaces, some architectonic typologies from the Virreinato or Inka's antique sacred contexts, can attach them magician and religious contents. This fact confirms the continuity of the sacred entities of the Andes in the established occidental architecture.
\end{abstract}

keywords: Petroglyphs, wakas, monolyths, stone sculture, stone graving, Cusco, Inkas, ideographies.

* Oficina Técnica del Centro Histórico del Cusco, Acuerdo Municipalidad del Cusco. Correo electrónico: germanyumi@yahoo.es. 


\subsection{Entidades sagradas y santuarios andinos}

Los antiguos habitantes de los Andes poblaron el territorio con una multiplicidad de entidades sagradas, dioses y seres enlazados a sitios geográficos o lugares vinculados con importantes acontecimientos de la mito historia andina; seres sobrenaturales cuya presencia daba sentido al espacio y a las actividades económicas desarrolladas en éste. Estas entidades divinas se conceptúan bajo el nombre de Waka.

Las palabras quechuas que designan a lo sagrado y divino son: Waka y Willka (Anónimo 1586: 87); vocablos que aluden al concepto de entidad sagrada en los objetos (sean naturales o manufacturados) y en los diferentes seres que conforman a la Naturaleza (recursos naturales o sitios donde ocurrieron hechos mito - históricos), dotándoles de cualidades y características sobrenaturales, poderes y atribuciones que les permitían intervenir en las actividades y decisiones humanas, por lo que requerían de complicados y aún hoy incomprendidos rituales y sacrificios.

El concepto de Waka se expresa de mejor manera en el culto a las grandes montañas denominadas: Apu; la veneración a las mismas se basaba en la creencia de que antiguamente habían sido personajes o héroes metamorfoseados en tales; igualmente, las formaciones telúricas: pukyos (manantiales) (Arriaga 1999 [1621]: 28), mach'ay (cuevas o grutas) (Farfán 1971: 589; Cusihuamán 1976) y paqarinas (cuevas o sitios de donde nacen los seres o se da el amanecer) (Anónimo 1586: 66; Cusihuamán 1976: 101; Arriaga 1999 [1621]: 30), mayu (rios), qochas (lagos o lagunas), la Mamaqocha (el océano) (Anónimo 1586: 158; Arriaga 1999 [1621]: 27), las apachetas (pasos o abras de los cerros) (Anónimo 1586: 16), las Koya (minas) (Anónimo 1586: 26), etc. ocupaban un sitio importante dentro de estos términos.

El cronista mercedario Fray Martín de Murúa puntualizó: “...estas huacas e ídolos, había por todo el Reino, sin número, en las provincias, en los pueblos particulares en los ayllos y tribus, en las casas y caminos, montes, cerros, cuevas, piedras, encrucijadas, árboles, de manera que, cualesquiera cosa que excedía los límites y términos ordinarios, y que era admirable... luego la adoraban y reverenciaban, y ofrecían sacrificios, y la tenían por negocio divino y sobrenatural...Las estrellas, el lucero, las cabrillas, las fuentes, manantiales, el arco del cielo..." (Murúa 2001[1590]:432).

De acuerdo a las relaciones escritas por los extirpadores de Idolatrías, las entidades sagradas andinas podrían clasificarse básicamente de dos maneras:

1. Los elementos naturales mayores como los astros (el Sol, la Luna, las principales estrellas y constelaciones) ${ }^{2}$, las elevaciones orogénicas (los grandes cerros nevados y principales cadenas montañosas, incluyéndose aquí a las afloraciones rocosas y accidentes geográficos), las masas de agua, los fenómenos naturales (la lluvia, el Arco Iris, el Rayo, el granizo, etc.);

2. Las deidades móviles (Arriaga 1999 [1621]: 30), es decir piedras o wankas (Farfán 1971: 581) ubicadas en medio de las sementeras, también conocidas como Chakrayoq (algunos con formas de los vegetales a los que protegen $)^{3}$,

\footnotetext{
El vocablo WAKA aparece escrito en la documentación correspondiente, como GUACA (Cobo 1980:15 [1653: Lib. 13, Cap. 13]) o HUACA (Polo de Ondegardo 1916a: 43 [1585]) (Anónimo 1586: 45). De acuerdo a la Academia Mayor de la Lengua Quechua, la grafía correcta es utilizando las letras W y K en sustitución de la G, H y C respectivamente. Esta normatividad se utilizará para todas las palabras quechuas indicadas en el presente trabajo (Academia Mayor de la Lengua Quechua 1995).

2 "En muchas partes (especialmente de la sierra) adoran al Sol, con nombre de Punchao, que significa el día, y también debajo de su propio nombre Inti. Y También a la Luna, que es Quilla, y a algunas estrellas, especialmente a Oncoy que (son las siete Cabrillas)". (Arriaga 1999 [1621]: 26-27).
} 
los caullam $a^{4} \mathrm{o}$ entidades protectoras del ganado (zoomorfos, a manera de illas o qonopas), y otras que cuidan las casas (algunas antropomorfas), así como las piedras con metal o korpas (Farfán 1971: 569) $)^{5}$; estos elementos aparecen como simples líticos o como complicadas estelas escultóricas, llenas de plano relieves o petroglifos. Entran a esta clasificación también los cuerpos embalsamados de los antepasados, denominados Mallki ${ }^{6}$.

\subsection{La piedra como entidad sagrada}

Frente a la existencia de estas divinidades emplazadas en el espacio y contexto natural, existió un nutrido cuerpo de santuarios que eran o se componían de elementos arquitectónicos: rocas labradas o afloramientos rocosos con muestras de tallas -tanto sobre sus superficies como en las cavidades de sus núcleos (Zecenarro - Quispe 2002a)-, paredes, recintos o edificios, complejos urbanos, explanadas ceremoniales y lugares de enterramiento o necrópolis (Zecenarro 2001b: 86-96).

En fin, entraban al campo santual todas aquellas formaciones naturales cuyas características telúricas permitían atribuirles contenidos y significados sagrados. Esta sería la razón de existir de los complejos labrados que ostentan las afloraciones calizas de la Meseta de Saqsaywaman, como las wakas: T'oqokachi, Teteqaqa, Laqo (Zecenarro - Quispe 2002a: 48-55), K'usilluchayoq, Lanlakuyoq, Chakan, Ch'eqtaqaqa, Qenqo, Sapantiana, Inkilltambo (Zecenarro 2001b), etc., en muchas de las cuales es notoria y característica la presencia de representaciones de entidades zoomorfas (pumas, aves, serpientes) e impresionantes relieves geométricos vinculados a la astronomía y religión (Zecenarro 2004a: 86-98).

Según los antiguos mitos, el enigmático dios Wiraqocha había creado en piedra a los primitivos hombres (Betanzos 1999: 11) ${ }^{7}$, y de piedra

\footnotetext{
3 "Chichic o huanca llaman una piedra larga que suelen poner empinada en sus chácaras, y la llaman también chacrayoc, que es el señor de la chácara, porque piensan que aquella chácara fue de aquella huaca, y que tiene a cargo su aumento, y como a talla reverencian, y especialmente en tiempo de las sementeras le ofrecen sus sacrificios" (Arriaga 1999 [1621]: 37).

4 "...Hay también conopas más particulares, unas para el maíz, que llaman zarap conopa; otras para las papas, papap conopa; otras para el aumento del ganado, que llaman caullama, que algunas veces son de figuras de carneros". (Arriaga 1999 [1621]:36).

5 "Pero haré una breve suma y diré como testigo de vista las huacas, hechiceros, conopas y otras cosas de idolatrías que se han hallado en los pueblos que visitó el doctor Hernando de Avendaño en año y medio que le acompañé. Y aunque pudiera decir muy en particular lo que en cada pueblo se descubrió.. lo diré solo por mayor, sumando lo particular de todos los pueblos de la primera visita, que se hizo desde febrero del año pasado de mil seiscientos y diecisiete hasta julio de mil y seiscientos y dieciocho. Son cinco mil seiscientas y noventa y cuatro personas las que se han confesado, seiscientos y setenta y nueve ministros de idolatrías los que se han descubierto, y penitenciado por tales, seiscientos y tres huacas principales que se les han quitado, y tres mil cuatrocientos y dieciocho CONOPAS, cuarenta y cinco mamazazas y otras tantas COMPAS, ciento y ochenta y nueve HUANCAS (estos son diferentes de las huacas), seiscientos y diecisiete mallquis..." (Arriaga 1999 [1621]: 22-23). "Compa o larca villana llaman otras piedras a este mismo modo que tienen en las acequias, a las cuales hacen la misma reverencia antes de sembrar y después de pasadas las aguas, porque las acequias no se les quiebren y les falte el agua" (Arriaga 1999 [1621]: 37). Las mayúsculas son nuestras.

"MALLKI equivale a "cuerpo embalsamado o momificado", así como es la palabra para designar filosóficamente a los árboles sagrados y también a los almácigos o sementeras (Farfán 1971: 589; Zecenarro 2001a: 152-154). Este concepto, que hace referencia a las especies vegetales mayores, se puntualiza en el dibujo del "Altar mayor" del Qorikancha de Juan Santa Cruz Pachacuti (Pachacuti Yamqui Salcamaygua 1993 [1613] f.13v: 208), donde el "árbol mallqui" integra un sitio importante dentro de la cosmogonía andina. Igualmente, Arriaga indica: “...para hacer concepto del miserable estado en que están y de la necesidad extrema que tienen de remedio y la facilidad y gusto con que le admiten, no es menester otro testimonio más que ver un día de las exhibiciones, que es cuando todos juntos traen todos los instrumentos de su idolatría. Parece un día de juicio; están repartidos en la plaza por ayllos y parcialidades; tienen consigo los cuerpos secos y enteros de sus antepasados, que en los llanos llaman Munaos y en la sierra
} 
eran también los temidos guerreros Purur Awqa que defendieron la llaqta del Qosqo durante el asedio de los Chanka ${ }^{8}$.

Para la mito historia andina, los seres fabulosos y los grandes personajes o héroes ${ }^{9}$ trascienden en el tiempo y en el espacio convertidos en piedra, como la waka Chinpu Qhawa (Chimpu Cahua) de los antiguos Sañu, roca sobre la cual Ayar Uchu Wanakawri quedó adherido y metamorfoseado en tal en las proximidades de la elevación orógena del mismo nombre (Sarmiento 2001 [1571]: 56-57); o de aquel "sierpe" o sapo mítico que venía sobre el Cusco, convirtiéndose en roca en las alturas de Wanakawri (Huanacaure) antes de alcanzar su objetivo ${ }^{10}$.

El relato acerca de Qosqo Wanka es mucho más importante y substancial por contener el simbolismo de la mítica fundación del Qosqo por parte de los hermanos Ayar (Zecenarro 2002, 2003b: 392). En éste, Ayar Awqa baja volando desde Wanakawri para posarse sobre un sitio pedregoso que se encontraba en el lugar que hoy corresponde al Qorikancha (actual Templo y Convento de Santo Domingo); al descender y posarse sobre las rocas, queda convertido en tal, dando su nombre: "Ayar Awqa Qosqo Wanka" , al lugar donde se asentaría la futura llaqta del Qosqo.

Igualmente, las referencias de Pachacuti Yamqui Salcamaygua vinculan la cumbre de Wanakawri con la metamorfosis de dos de los míticos hermanos, en sendas rocas: los mágicos picachos Sawasiray -Pitusiray, topónimos que aluden a los cerros nevados que todavía dominan el Valle Sagrado de los Inkas (Pachacuti 1993[1613] 194-196; Guaman Poma 1956 [1616]: 436).

Grandes roquedales son también los sitios preferidos para servir de tumbas a las momias o mallkis (Farfán 1971: 589), que se cobijan en sus grietas por las que se filtran los rayos solares; y la piedra es el material constructivo por excelencia en los Andes, con el cual se levantan los principales edificios. Aún en los sitios importantes donde no existe naturalmente o donde se reque-

Mallquis..." (Arriaga 1999 [1621]: 21). "Después de estas huacas de piedra la mayor veneración y adoración es la de sus mallquis, que en los llanos llaman munaos, que son los huesos o cuerpos enteros de sus progenitores gentiles, que ellos dicen que son hijos de las huacas, los cuales tienen en los campos en lugares muy apartados, en los machays, que son sepulturas antiguas..." (Arriaga 1999 [1621]: 34). Los resaltados son nuestros.

7 "... dicen que hizo el sol y día, y luna y estrellas; y que esto hecho, que en aquel asiento de Tiaguanaco, hizo de piedra cierta gente y manera de dechado de la gente que después había de producir, haciéndolo de esta manera: Que hizo de piedra cierto número de gente y un principal que la gobernaba y señoreaba y muchas mujeres preñadas y otras paridas y que los niños tenían en cunas, según su uso; todo lo cual ansí hecho de piedra..." (Betanzos 1968: 9). El resaltado es nuestro.

${ }^{8}$ Los líticos sagrados que representaban a los guerreros Purur Awqa se hallaban en diferentes partes del Cusco, conformando parte de la trama santual de la llaqta. Así por ejemplo, el Licenciado Polo de Ondegardo, al referirse al quinto seqe con dirección a Chinchaysuyo, indica: "La tercera Guaca se decía Cuzocallá; estaba en la calle que sale a la plaza yendo por esta raya o Ceque, y era buena cantidad de piedras, que todas decian ser de los Pururaucas" (Polo de Ondegardo 1917 [1571]: 5).

9 "el primer ceque e decia, cayao, estaua a cargo de la parcialidad, y Ayllo de Goacaytaqui, y tenia los cinco Guacas siguientes... la primera se llamana, Michosamaro, estana arrimada a la falda del cerro de Totocache (T'oqokachi, actual Barrio de San Blas); y decian ser uno de aquellos que fingieron hauer salido con el primer inca Manco capac de la cueba de Pacaritampu. Al qual refieren que una muger de las que salieron con ellos de la dicha cueba le mato por cierto desacato que con ella tubo, y se torno piedra, y que su anima se aparecio en este mismo lugar, y mando que le sacrificasen alli; y asi fue el sacrificio desta Guaca muy antiguo; el qual se hacia siempre de oro, ropa, conchas de la mar, y otras cosas; y soliase hacer por buenos temporales". (Cobo 1980 [1653] Cap. 13). Los resaltados y paréntesis son nuestros.

${ }^{10}$ Relato recogido de los comuneros de T'ankarpata, en las faldas del cerro Wanakawri (octubre 1995).

${ }^{11}$ Mayores alcances acerca del topónimo "Ayar Awka Qosqo Wanka”, origen y significados del mismo dentro de las lenguas andinas, en (Cerrón-Palomino 2004: 12). 
ría de un lítico en particular proveniente de la misma llaqta sagrada del Qosqo, las piedras fueron transportadas en medio de solemnes rituales religiosos ${ }^{12}$.

La piedra connota a la inmortalidad y es el modo de existencia de las divinidades andinas. Es el elemento telúrico que simboliza la trascendencia en el espacio y tiempo, y por eso los héroes míticos se convierten en tales o las entidades de la naturaleza las escogen para morar; la relación entre los hombres con la naturaleza se da a través de la piedra u objetos derivados. Estos pormenores permiten entender la razón del culto a la pie- dra en el mundo prehispánico - especialmente entre los Inkas -, además de acercarnos someramente a sus significados y contenidos mágico religiosos, gran parte desaparecidos o mutilados a causa de la destrucción sistemática emprendida en el siglo XVI por los ideólogos europeos.

\section{Wakas y piedras sagradas del cusco}

El padre José de Acosta calificó a la ciudad del Cusco (Fig. 1) como una "tierra santa", cuyos parajes estaban preñados de misterio y que existían alrededor de cuatrocientos adoratorios o wakas $^{13}$, de los cuales -de acuerdo a la relación

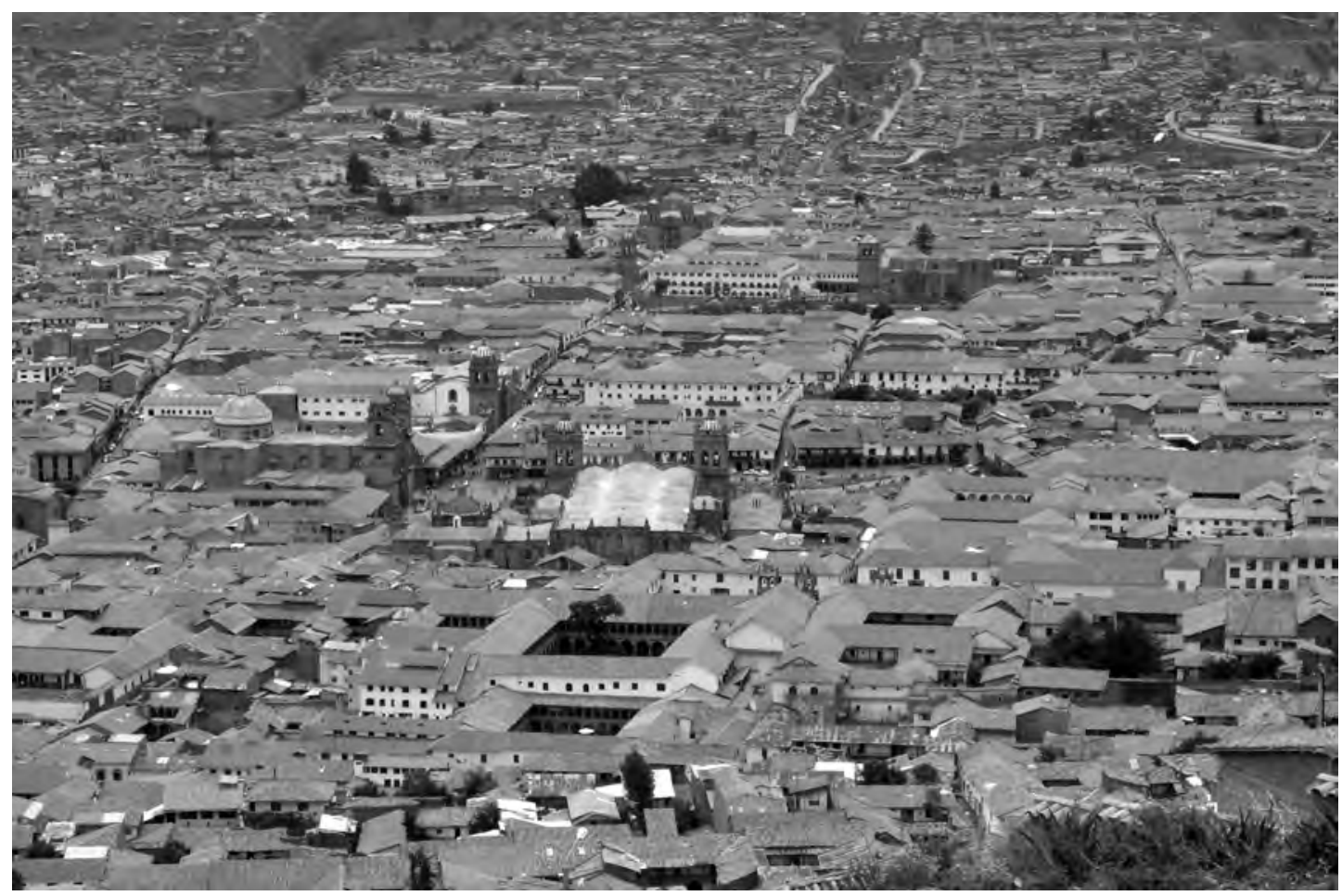

Figura 1. La ciudad del Cusco.

\footnotetext{
${ }^{12}$ Es muy sugerente la ilustración de Guaman Poma de Ayala, donde se verifica el traslado entre Cusco y Huanuco de una piedra -elementos de este tipo que popularmente se conocen como "piedras cansadas"-, que fue considerada sagrada porque "lloró sangre" (Guaman Poma 1956 [1616]: 375). Igualmente, Cobo relata el traslado de piedras sagradas a lugares tan distantes como Quito. Es el caso del monolito Wanakawri: "Llevaban este ídolo á la guerra muy de ordinario, y particularmente cuando iba el Rey en persona; y Guayna Capac lo llevó a Quito, de donde lo tornaron á traer con su cuerpo. Porque tenían entendido los Incas, que había sido gran parte en sus victorias. Poníanlo para la fiesta del Raymi ricamente vestido y adorando de muchas plumas encima del dicho cerro de Huanacauri" (Cobo 1956: 64).
} 




Figura 2. Esquina de

las calles Zetas y

Awaqpinta, en el

sector del Qorikancha.

rados sagrados, cuya manifestación física era a través de las piedras.

Los elementos líticos constituyeron parte de la organización espacial de la misma llaqta, emergiendo como puntos focales o hitos en determinados parajes neurálgicos de la trama urbana (Fig. 02).

Igualmente, estas manifestaciones santuales aparecían en las mismas edificaciones, al

escrita por el jesuita Bernabé Cobo (Cobo 1980 [1653] Cap. 13) -, muchos eran piedras o roquedales con características propias, cuya singularidad los distinguía dotándoles de connotaciones sacras.

De la misma forma, el Licenciado Juan Polo de Ondegardo escribía que:

"...el Cuzco y su comarca tenía gran suma de Idolos, huacas, villcas, adoratorios ó mochaderos, constituydos en diferentes partes [...] la Ciudad del Cuzco era casa y morada de dioses e ansí no avía en toda ella fuente ny paso ny pared que no dixesen que tenya mysterio..." (Polo de Ondegardo 1916a [1585]:43; 1916b [1571]: 55).

La actual ciudad del Cusco y alrededores aún atesoran muchos vestigios que testifican lo arraigado que estaba el culto a los seres conside- nivel de detalle constructivo, estructural u ornamental. Una piedra sagrada podía formar parte de la estructura de un muro de carga o de contención, y su connotación sacra quedaba expresada mediante la adaptación arquitectónica del paramento a la forma natural de la misma, de tal forma que el muro protegía y embellecía a la roca primigenia o preexistente, que podía ser parte de un afloramiento rocoso considerado como waka.

Las piedras con múltiples ángulos que forman parte de aparejos de paramentos en Saqsaywaman, Tambomachay, Hatunrumiyoq (12 ángulos) (Fig. 3), Lanlakuyoq (más de 15 ángulos) o Torontoy (48 ángulos), etc., podrían basar su explicación en lo mencionado.

Se puede afirmar que la roca diorítica que ostenta la huella de un plantígrado - hoy en Huch'uy Rimaqpanpa (Limacpampa Chico) (Fig.

\footnotetext{
13 "Había en Cuzco más de cuatrocientos adoratorios, como tierra santa, y todos los lugares estaban llenos de misterios..." (Acosta 1954 [1590]: 199).
} 
04)-, fue parte de los mampuestos de un lienzo de muro; embutida estructuralmente dentro del mismo. Posiblemente respondió a las connotaciones mágicas de una waka en particular, cuyo nombre y significados se desconocen por completo.

Estas mismas características presentaba la roca escalonada que se aprecia en Chakan (parte alta del río Saphy), un singular elemento labrado in situ que conformó parte de un muro perimetral que "vestía" al afloramiento calizo, bajo el cual discurre el río de este nombre.

Las características de tamaño y forma de las wakas permitían también su transporte, pues algunas eran objetos móviles que podían ser llevados de un sitio a otro como parte de ceremonias rituales. El hecho de que la waka sea transportable está señalando a objetos pequeños, monolitos de regular tamaño, litoesculturas o estelas, así como estatuas en metal precioso, y principalmente mallkis o momias de los antepasados $^{14}$. Las crónicas (Cobo 1956: 64) refieren que durante el viaje o transporte de la waka, utilizando andas o ranpa, éstas se acompañaban de un séquito aprovisionado para tal fin, además de ir "ataviadas" con sus mejores trajes y ornamentos, y en el trayecto se realizaban sacrificios y rituales en su honor.

Todavía está vigente el acto de transportar o llevar en procesión a las wakas y entidades sagradas, actividad inmersa de contenidos y significados andinos pero a través de envolventes y for-

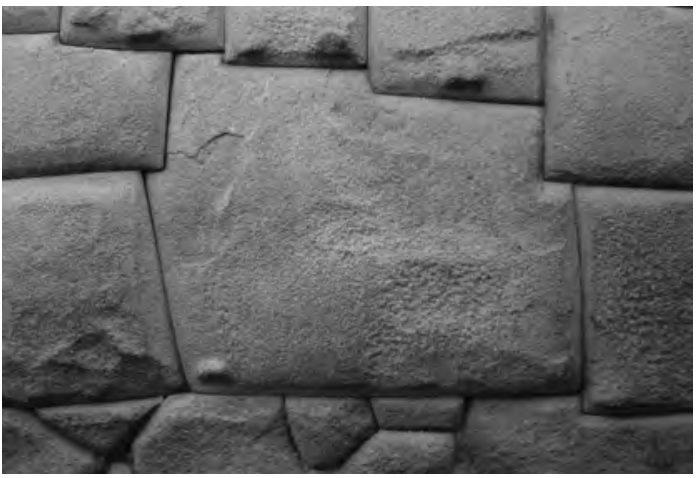

Figura 3. Piedra de los Doce Ángulos. Muro del usnu de Hatunrumiyoq.



Figura 4. Huella de plantígrado, pieza de diorita verde actualmente conservada en la Plazoleta Rimaqpanpa Chico (Limacpampa Chico).

mas externas occidentales. Las esculturas de los santos católicos que se presentan durante la festividad del Corpus Christi son una clara expresión de ello, demostrándose así la persistencia y fuerza de la ideología andina a través de los siglos. Basta citar como ejemplos a San Sebastián

${ }^{14}$ El transporte ritual de las wakas está valiosamente documentado en múltiples referencias de los cronistas, así como en los gráficos de Guaman Poma, (Guaman Poma 1956 [1616]: 375, 427, 451). El gráfico más interesante, es aquel donde se observa a Tupaq Inka Yupanki realizando un dialogo con las wakas congregadas al pie de la waka de Wanakawri. El texto que refrenda esto es el siguiente: "topa ynga yupanqui hablaua con las uacas y piedras y demonios y sauia por suerte de ellos lo pasado y lo tenedero de ellos y de todo el mundo..." (Guaman Poma 1956 [1616]: 431) (Fig. 6). Esta costumbre andina de reunir a las wakas se documenta con la referencia de Cobo: "El segundo ceque del dicho camino de Antisuyu se decia payan, y tenia diez guacas. La primera era un lugar llamado Vilcacona, donde se edificó la casa que fue de Juan Salas. A este adoratorio llevaban en cierto tiempo del año todas las guacas é ídolos de la ciudad del Cuzco, y allí juntas les sacrificaban, y luego las volvían á sus lugares..." (Cobo 1956: 40); y con los comentarios de admiración de Pedro Pizarro, cuando narra la costumbre de llevar a las momias o mallkis de los antepasados a la plaza del Cusco, para "comer" y "beber" (Pizarro 1986: 89). Igualmente, muchos mallkis eran llevados a las punas y cultivos con el fin de propiciar lluvias (Zecenarro 2001a: 167-168). 
(escultura del artista Melchor Huaman Mayta, siglo XVII), que viene a ser la representación del árbol Mallki, o a la colosal obra del artista Juan Tomás Tuyru Tupaq Inka: San Cristóbal, patrono de la parroquia del mismo nombre, imagen del siglo XVII que lleva dientes y uñas naturales posiblemente pertenecientes a alguna momia Inka vinculada a Qollqanpata, nombre andino de esta parroquia fundada por Cristóbal Paullu Inka Waka Tupaq en el siglo XVI (Benavente 2006: 115-122).

Las piedras transportadas ritualmente desde la llaqta del Qosqo a otros sitios o viceversa, debieron adquirir esta jerarquía sagrada al constituir y formar parte de los muros o ubicaciones a donde eran destinadas.

Igual connotación se atribuye a las piedras denominadas wanka, monolitos hincados verti-

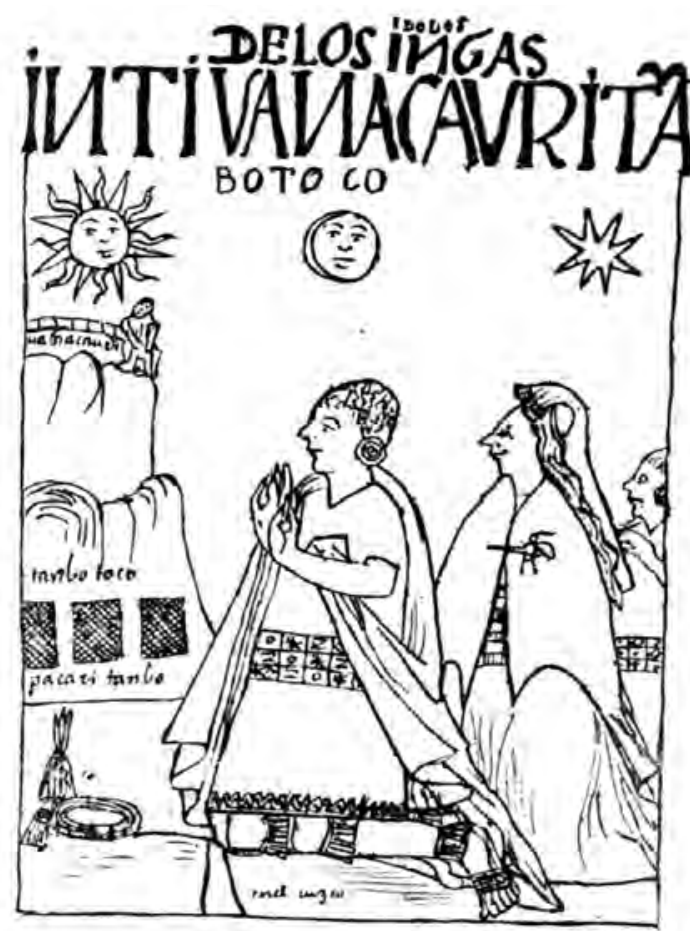

Figura 5. Representación gráfica de la waka de Wanakawri (Huanacaure). Dibujo de Felipe Guamán Poma de Ayala (1956 [1616]: 188/433). calmente sobre las explanadas ceremoniales o los campos de cultivo, adquiriendo en este último caso el nombre de chakrayoq (Arriaga 1999 [1621]: 37; Farfán 1971: 571); o aquellas que se encontraban al borde de los canales de regadío, conocidas bajo el nombre de larkawillana (Arriaga 1999 [1621]: 37; Farfán 1971: 586). Estos monolitos son muy comunes en toda la historia del Arte Prehispánico, apareciendo desde los más simples a las elaboradas estelas escultóricas, llenas de plano relieves, ideografías o petroglifos.

Es importante también mencionar al monolito que estuvo en la cima del cerro Wanakawri (Huanacaure). Esta piedra wanka (Farfán 1971: 581)era la manifestación física de Ayar Uchu Wanakawri [Qo. 6:7], un monolito de tamaño mediano y de forma ahusada (Cobo 1956 [1653]: Citado de Bauer 2000: 195). La representación iconográfica del mismo se encuentra en los dibujos de Felipe Guaman Poma de Ayala (1956 [1616]: 188/433), en donde aparece como una escultura antropomorfa, que remata en esta importante y mítica montaña vinculada con la fundación de la ciudad del Cusco (Fig. 5).

Desde tiempos legendarios fue exaltado y reverenciado por los ayllus Inkas como una de sus principales divinidades tutelares. En muchas oportunidades, la waka fue transportada ricamente ataviada, a escenarios de batallas y ceremonias, e incluso, a sitios distantes como Quito, en el Ecuador actual, de donde retornó junto con el cuerpo momificado de Wayna Qhapaq Inka. Durante los primeros años de la invasión europea, después del saqueo y destrucción de su santuario en la cima del cerro, la waka permaneció oculta en las propiedades de Cristóbal Paullo Inka en Qollqanpata (Parroquia de San Cristóbal), hasta su lamentable hallazgo y destrucción por parte de los extirpadores de idolatrías (Zecenarro 2003b; Zecenarro 2006a, cit. en Benavente 2006: XVIII) ${ }^{15}$.

\footnotetext{
15 "La sétima se llamaba Huanacauri, la cual era de los más principales adoratorios de todo el reino... Este es un cerro que
} 
Otro ejemplo de la presencia de entidades sagradas dentro del conjunto urbano Inka, lo constituían las piedras Purur Awqa que existían en el Cusco ${ }^{16}$ y el sitio o receptáculo arquitectónico donde estaban colocadas. Así, la waka Racramirpay [Ch. 2:2], estaba puesta en una "ventana" más abajo del templo de San Agustín $^{17}$, posiblemente cerca y similar en posición a las "ventanas" - técnicamente nichos que aparecen tapiadas en los muros de la casa de Juan de Salas y Valdés, en la hasta hace poco denominada Calle Romeritos.

Estos nichos construidos con vista a la calle o k'ijllu, conformaban en este caso el contexto urbano del sector denominado Willkakuna [An. 2:1] ("los dioses" en su traducción literal), un importante adoratorio donde eran reunidas todas las divinidades (Zecenarro 1996: 128-130; 2001a: 63; 2005b), haciendo de este sector, vecino al Qorikancha y al Kusikancha, un lugar de alta estima por la particularidad de congregar divinidades posiblemente en determinadas ceremonias regidas por el complejo calendario ritual Inka (Fig. 6).

Pero no sólo los acontecimientos míticos podían estar relacionados con la razón de existencia de estas piedras divinas, también hay casos sobre hechos históricos registrados que permitieron la atribución de significados sagrados a un elemento lítico. En 1572, una piedra fue instituida como waka por haberse consumado sobre ella el sacrificio del Inka Tupaq Amaru (Figs. 7 y 8); una valiosa muestra de una waka concebida en pleno periodo de Transición (Teófilo Benavente Velarde, comunicación personal) ${ }^{18}$.

Este monolito era objeto de alta estima, y estuvo por mucho tiempo en el mismo sitio donde el Virrey Toledo ordenó la ejecución del Inka, es decir la Plaza del Cabildo. Posteriormente fue llevado al sector de

dista del Cuzco como dos leguas y media por este camino en que vamos de Collasuyu, en el cual dicen que uno de los hermanos del primer Inca se volvió piedra, por razones que ellos dan, y tenían guardada la dicha piedra, la cual era mediana, sin figura y algo ahusada. Estuvo encima del dicho cerro hasta la venida de los españoles, y hacíanle muchas fiestas. Mas luego que llegaron los españoles, aunque sacaron deste adoratorio mucha suma de oro y plata, no repararon en el ídolo, por ser, como he dicho, una piedra tosca; con que tuvieron lugar los indios de esconderla, hasta que, vuelto de Chile Paullu Inca, le hizo casa junto á la suya; y desde entonces s hizo allí la fiesta del raymi, hasta que los cristianos la descubrieron y sacaron de su poder. Hallóse con ella cantidad de ofrendas, ropa pequeña de idolillos y gran copia de orejeras para los mancebos que se armaban caballeros" (Cobo 1956: 63-64).

${ }^{16}$ De acuerdo a la mito-historia andina, durante la guerra contra los Chankas las piedras se volvieron en guerreros por voluntad del dios Wiraqocha, intervención sobrenatural que inclinó la victoria hacia los Inkas. Estos guerreros de piedra recibieron el nombre de purur awqa, y se encontraban ubicados -bajo distintas denominaciones- en diferentes partes del Cusco, como se indica en la relación de santuarios de Bernabé Cobo (Cobo 1956: 15, 20-21, 24, 26, 28-29, $54,65,67,69,70,73-76)$. La alusión al mito de los Purur Awkas la brinda Cobo de la siguiente manera: "...la segunda Guaca se llamaua, Racramirpay; esta era una piedra que tenian puesta en una ventana que estaua un poco mas abajo de donde aora es el conuento de San Agustin; cuya historia refieren desta manera: que en cierta batalla (se refiere a la Guerra contra los Chankas) que dio inca yupanqui a sus enemigos (Pachakuteq, vencedor de los Chankas), se le aparecio un indio en el ayre, y le ayudo a uencerlos. y después de alcançada la vitoria, se vino al cuzco con el dicho inca, y sentandose en aquella ventana se conuirtio en piedra: la qual desde aquel tiempo adorauan, y le hacian sacrificio ordinario. y particularmente se le hacia solemne quando el inca yua personalmente a la guerra, pidiendole que ayudase a Rey como havia ayudado a inca yupanqui e aquella guerra". (Cobo 1980 [1653] Cap. 13). Los resaltados y paréntesis son nuestros.

${ }^{17}$ Hoy calle Ruinas, o "Ruinas de San Agustín". En la actualidad, definiendo esta vía y la calle San Agustín, quedan todavía parte de los claustros y la portería de este desaparecido Convento.

${ }^{18}$ Sobre los postreros días del Inka Felipe Tupaq Amaru y la ubicación de su tumba en la Sala Capitular del convento dominicano del Cusco, se han realizado diversos estudios, entre los que destaca la obra -aún inédita- del Maestro Teófilo Benavente Velarde, sobre tumbas ilustres en las criptas o naves de los Templos cusqueños. 


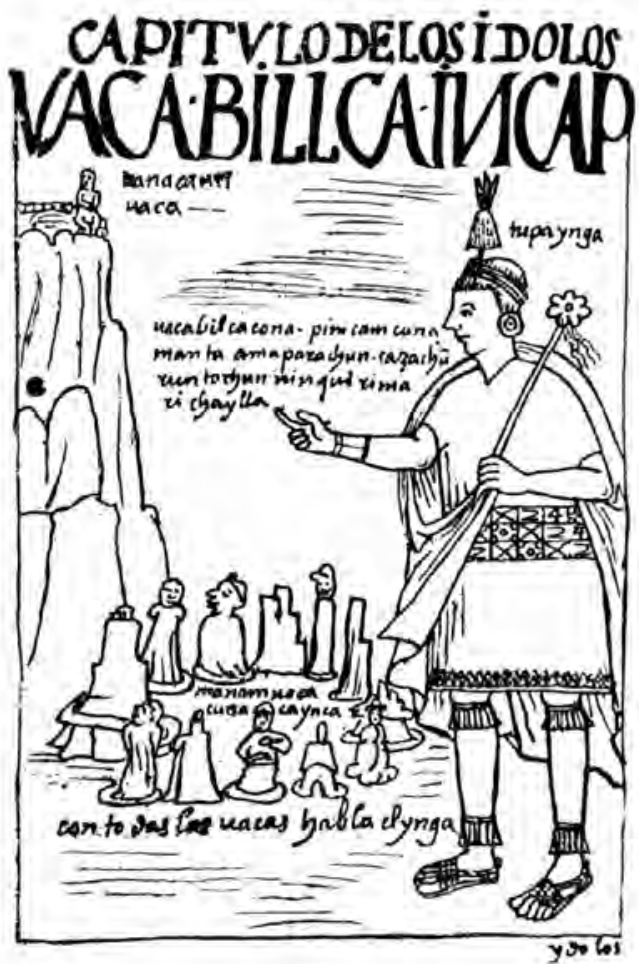

Figura 6. Wakawillkakuna. Congregación de todas las wakas. Dibujo de Felipe Guamán Poma de Ayala (1956 [1616]: 431).

Quillinsacata -posiblemente la calle Procuradores-, para luego -en 1834-, aparecer en el espacio frontero del Colegio de San Francisco de Borja; hoy está desaparecido, como muchas expresiones y símbolos de la Cultura Andina ${ }^{19}$. José María Blanco indica que esta piedra era muy respetada por la gente, por ser el ara donde se consumó el sacrifico de la Nación andina (Blanco 1974).

Actualmente, en muchas partes de la ciudad del Cusco algunas piedras sagradas aún mantienen su muda vigencia, la cual puede ser leída por

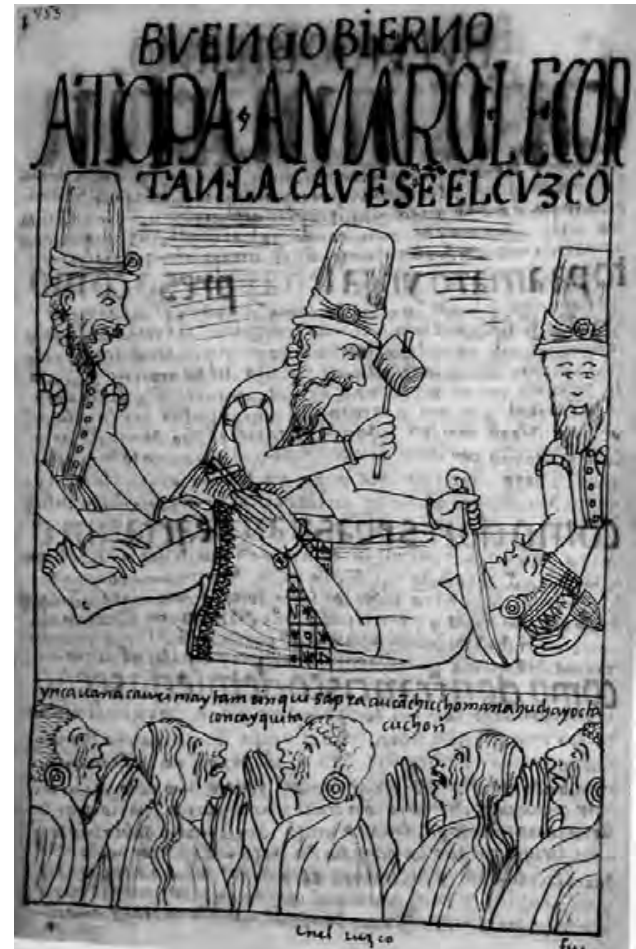

Figura 7. Sacrificio del Inka Tupaq Amaru. Dibujo de Felipe Guamán Poma de Ayala.

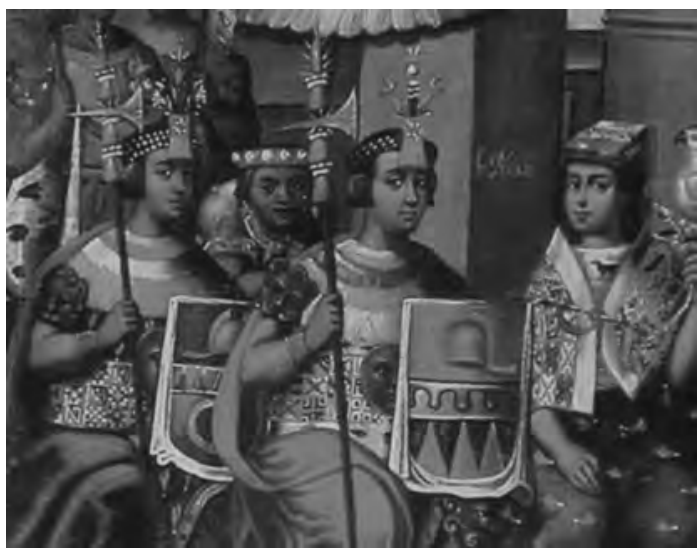

Figura 8. El Inka Tupaq Amaru (al centro). Detalle del lienzo del entroncamiento de la dinastía Inka con la familia de San Francisco de Borja y San Ignacio de Loyola. Templo de la Compañía de Jesús. Cusco.

\footnotetext{
${ }^{19}$ Hasta inicios de la década de los 90, en el espacio frontero del Colegio de San Francisco de Borja, estuvo ubicado un monolito de diorita verde, quizás relacionado con el que comentamos. Lamentablemente, las intervenciones urbanas contemporáneas no respetaron su contexto, y el monolito fue trasladado para cumplir la función de tranquera en la calle Hatunrumiyoq.
} 


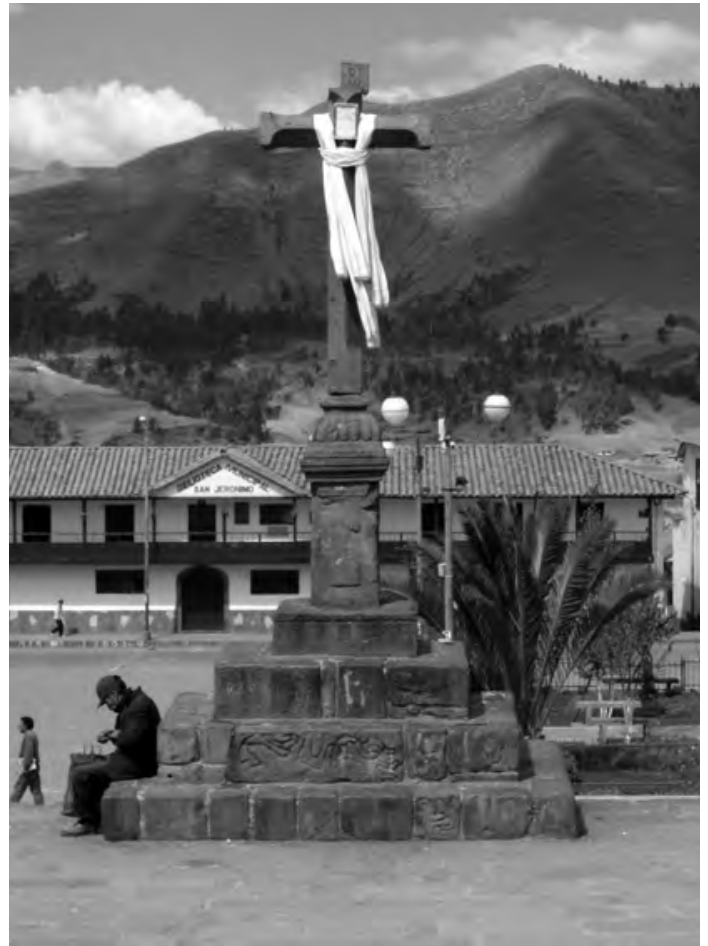

Figura 9. Cruz lítica en el atrio del templo parroquial de San Jerónimo (Cusco). Es notoria la presencia de petroglifos en las piezas que componen el pedestal.

la presencia de cruces asociadas (Fig. 9) o por los vestigios de pretéritas wakas que existieron en el lugar; basta citar como ejemplos a una piedra tronco cónica situada en la casa Guevara (Cuesta de Santa Ana № 601) (Valencia 1991: 117118), los bloques de diorita con atributos masculinos y femeninos que aparecen sobre el andén Chaqnapata en la Calle Santa Clara (antiguo andén de San Buenaventura y parte del camino al Kontisuyo) (Fig. 10), el monolito de Qollqanpata (Colcampata) (Fig. 11), posiblemente vinculado a una waka Antasaya, y la acrótera del Monasterio de Santa Catalina de Siena (Valencia 1991: 117), entre otras (Fig. 12).

Posiblemente dentro de estos conceptos y bajo esta misma connotación, se puedan situar aquellas piedras y/o elementos votivos en cuyas caras aparecen una serie de misteriosas así como

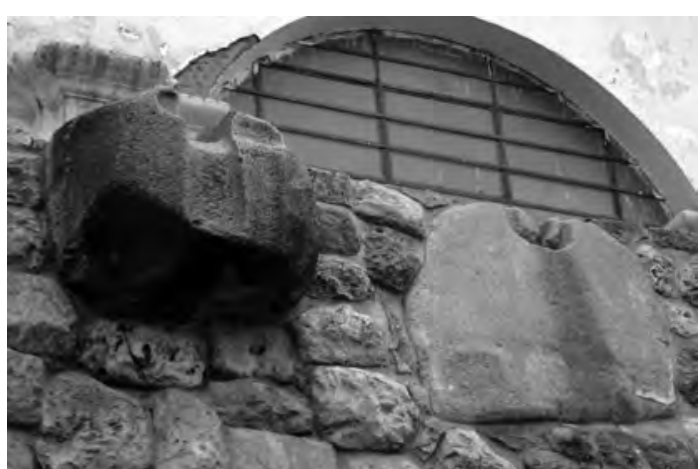

Figura 10. Piezas líticas con atributos masculinos y femeninos, en el andén Chaqnapata. Calle Santa Clara.



Figura 11. Monolito en Qollqanpata (Colcampata), posiblemente relacionado con una waka Antasaya. San Cristóbal, Cusco.

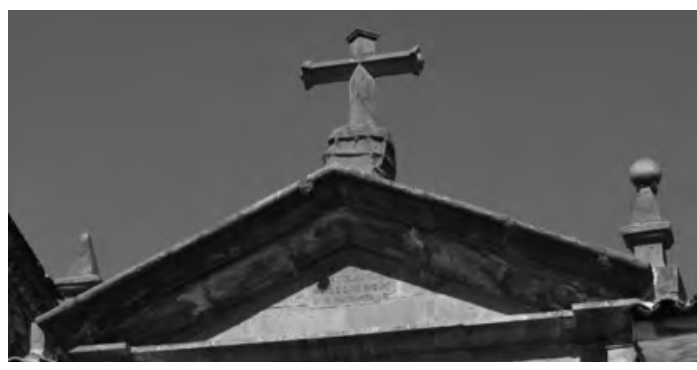

Figura 12. Acrótera sobre el frontón nuevo del Monasterio de Santa Catalina.

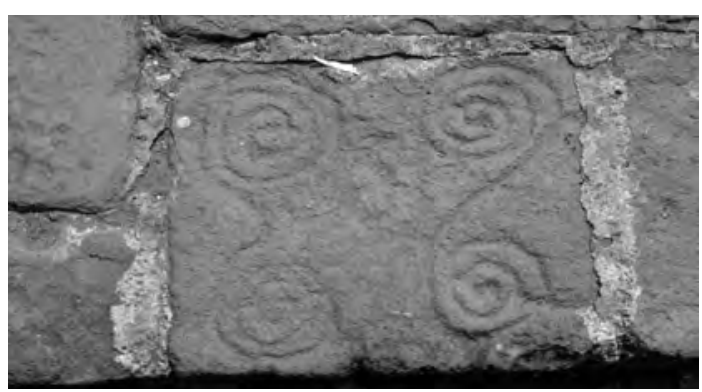

Figura 13. Petroglifo del atrio del Templo de San Jerónimo. Cusco. 
enigmáticas ideografías a manera de plano relieves sinusoidales y espiraloides. Estos petroglifos se hallan asociados principalmente a edificaciones virreinales de corte religioso, construidas a partir del siglo XVI como superposición ideológica, bajo el objetivo de cristianizar el mundo Andino (Fig. 13).

\section{Petroglifos y relieves sagrados}

Los elementos escultóricos o pictóricos que complementaban a las estructuras o complejos arquitectónicos prehispánicos no deben ser estudiados ni contemplados bajo conceptos estéticos simplemente. Estas representaciones plásticas expresaron y aún encierran una serie de contenidos mágico-religiosos vinculados íntimamente con el culto a los astros y a la misma naturaleza, considerada como la madre telúrica o pachamama. La religión se manifestó culturalmente a través de una simbología e iconografía muy propia y singular, que para llegar a la sociedad que los crea utiliza la expresión plástica como vehículo.

La creación pura de formas artísticas no se comprende en el mundo prehispánico si no lleva implícita la interpretación abstracta de la naturaleza a través de contenidos mágico-religiosos.

Bajo estas proposiciones debe entenderse la existencia de una serie de elementos líticos sobre cuyas caras se labraron o tallaron enigmáticas incisiones o marcas de morfología muy particular, así como la presencia de relieves o litoesculturas labrados in situ, como parte de las arquitecturas compactas que aprovechan de los afloramientos rocosos para manifestarse.

Posiblemente correspondan a la expresión de los sentimientos y contenidos mágico religiosos de la sociedad andina prehispánica, o a la grafía que los manifestaba físicamente y que solo podía ser entendida por sacerdotes e iniciados. Pero, por el momento, la interpretación de esta complicada simbología queda dentro de los planteamientos hipotéticos, pues, los códigos que permiten su lectura son aún campo de investigación, ya que en la mayoría de los casos fueron destruidos por el fanatismo religioso de los siglos XVIy XVII.

\subsection{Los petroglifos}

Actualmente, en el Cusco y su región quedan importantes vestigios de este tipo de expresión cultural que, por su relación o vinculación con determinados espacios urbanos, tipologías arquitectónicas virreinales o antiguos contextos sagrados del espacio santual Inka, se les puede atribuir contenidos mágicos que permiten su lectura como elementos componentes del vasto mundo religioso andino.

En términos generales se cuentan con estelas o monolitos o, bloques de piedra de diferentes tamaños asociados a edificaciones levantadas a partir del siglo XVI, cuyas representaciones o temas expresados sobre sus superficies, por estar realizados en un material perdurable, han sobrevivido al paso del tiempo y los agentes.

Pero el hecho de que los paramentos prehispánicos de adobe -o los enlucidos que componían los muros del tipo pirqa-, no hayan perdurado en el Cusco, no descarta la posibilidad de la existencia de bajorrelieves o plano relieves sobre ellos, así como también es factible la presencia de policromía como un complemento a éstos.

Técnicamente, estas incisiones sobre las superficies de la piedra reciben el nombre de petroglifos, y la forma de trabajo se denomina planorrelieve. La palabra (proveniente de los vocablos griegos: = roca; $\mathrm{y}=$ grabar, tallar), alude a los grabados rupestres con intencionalidad simbólica, realizados por las diferentes culturas de la protohistoria en el orbe ${ }^{20}$. Si bien la presencia de petroglifos es en gran parte de América y el Perú,

\footnotetext{
${ }^{20}$ La Epigrafía se refiere al estudio de textos o caracteres alfabéticos antiguos, escritos sobre piedra bajo la misma técnica.
} 
en el caso del Cusco el origen de estos elementos posiblemente esté vinculado con los motivos simbólicos e iconográficos de la antigua sociedad andina Pukara y en las inmemoriales costumbres Qolla (Kauffmann Doig 1983: 288-294), pues Ramos Gavilán y Calancha mencionan la existencia de petroglifos como elementos vinculados al dios Tunupa. Especialmente describen losas líticas con huellas de pies o cuerpos humanos en reposo, e incluso concavidades que las calificarían como piedras para arrodillarse (Valcárcel 1971: 439-440). Estos monolitos presentaban una serie de incisiones a manera de signos que los extirpadores de idolatrías adjetivaron como raros.

En general, estos petroglifos son incisiones sobre la piedra que siguen un patrón de dibujo lineal (Fig. 14). Se trata de glifos o surcos curvos que describen trayectorias en espiral quezás rememorando remolinos de viento o de agua, o el sentido de los líquidos al desaguar por el agujero de un recipiente, e incluso la forma de la cola que presenta el mono de las líneas de Nazca -; o bien, líneas sinusoidales (quizás expresando las dinámicas formas que produce el movimiento de las serpientes) (Fig. 15). Igualmente aparecen círculos, a manera de puntos, y rayas o marcas, acaso restos de una enigmática y misteriosa forma de escritura, cuya grafía nos es hoy totalmente desconocida.

La percepción de la mentalidad europea frente a estos elementos fue interesante. En unos casos se atribuyeron a grafías demoníacas que debían destruirse sistemáticamente por fomentar la idolatría y en otros casos, por exteriorizar coincidencias con signos conocidos, se los utilizó para "demostrar" la presencia de los Apóstoles en tierras andinas (Fig. 16); postulados que sucumbieron a partir de 1571, con la presencia del Virrey Francisco de Toledo.

En la zona de Calango, cerca a Lima, Calancha vio personalmente en 1615 una losa que traía signos a manera de letras griegas y

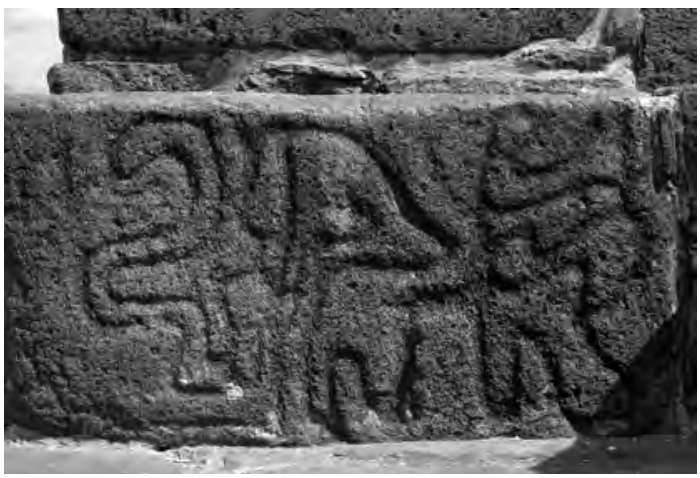

Figura 14. Petroglifo del atrio del Templo de San Jerónimo. Cusco



Figura 15. Petroglifo del atrio del Templo de San Jerónimo. Cusco.

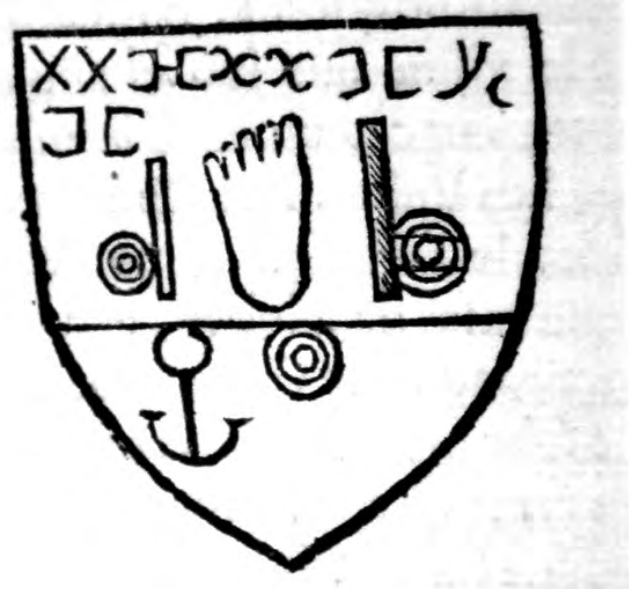

Figura 16. Reproducciones que trataban de demostrar la presencia de los Apóstoles de Cristo en América. Gráfico de la Crónica moralizadora del orden de San Agustín en el Perú. Fray Antonio de la Calancha. 
hebreas $^{21}$, y luego refiere sobre una piedra con las impresiones de un cuerpo humano yacente. Desdichadamente, ambas muestras fueron destruidas en 1625 por el Licenciado Duarte Fernández.

\subsection{Petroglifos en la arquitectura cusqueña}

Estos elementos son muy comunes en la zona andina, existiendo losas de este tipo relacionadas a un numeroso y nutrido cuerpo de mitos y leyendas. Generalmente ostentan huellas o plantas de pies humanos e incluso patas de plantígrados, como aquella encontrada en una casa de la calle Santa Catalina Ancha, hoy colo-

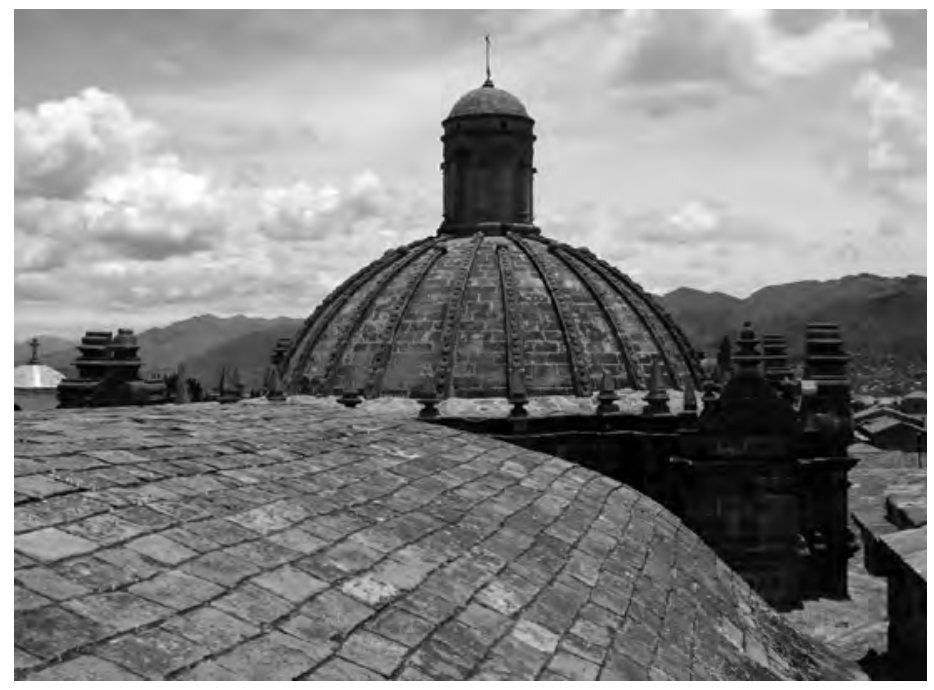

Figura 17. Cúpula del Templo del Triunfo. Los pilares que la sostienen marcan todavía el emplazamiento del antiguo Sunturwasi de los Inkas. cada como ornamento de la plazoleta Limacpampa Chico en el Cusco (Fig. 4). Esta pieza, trabajada en diorita verde, pudo corresponder a un mampuesto de un lienzo murario como indicamos anteriormente; una waka que estuvo colocada en los muros de contención de algún terraplén sagrado.

De la misma forma, es importante rememorar la existencia de una famosa "piedra blanca" posiblemente caliza calcárea - que existía a manera de tabernáculo bajo la cúpula de media naranja del templete del Triunfo (Fig. 17), estructura que quedó encerrada dentro de los muros del actual Templo del Triunfo, por obra del Obispo carmelita Bernardo Serrada (siglo XVIII) ${ }^{22}$. Esta piedra fue muy venerada durante todo el Virreinato y la República, por haberse posado encima la Virgen María ${ }^{23}$ durante el famoso Sitio del Cusco por el ejército de Manqo Inka, en mayo de 1536, como lo narran las dos lápidas existentes en los muros del Templo del Triunfo (Fig. 18). Las referencias históricas describen también una característica fundamental de esta "piedra blanca": la existencia de dos plantas de pies femeninos $^{24}$ sobre su superficie (Teófilo Benavente Velarde, comunicación personal).

\footnotetext{
${ }^{21}$ Signos como éstos permitieron fundamentar a los evangelizadores la presencia en América de los Apóstoles cristianos, como San Bartolomé o Santo Tomás, identificados con dioses andinos. Mayores datos al respecto en (Gisbert 1994).

${ }^{22}$ Los pilares que sostienen los arcos torales de la cúpula marcaban la planta del antiguo Sunturwasi, lo cual se reforzaba por la presencia de unas verjas metálicas intercaladas entre los mismos; estas verjas, de acuerdo a José María Blanco, además de dificultar el paso en la nave, estaban fomentando una narración supersticiosa, por lo que fueron quitadas por orden de Pío de Tristán en 1821 (Blanco 1974).

${ }^{23}$ El padre Blanco menciona la presencia de una escultura lítica de la Virgen María, "tal cual la vieron descender del cielo los indios para apagar el incendio del Sondorhuasi". Ésta se encontraba encima de un altar situado al medio del enrejado que formaban las verjas intercaladas entre los pilares de la cúpula (Blanco 1974).

${ }^{24}$ En la Basílica de San Sebastián, en Roma, existe una piedra con la incisión de dos pies humanos que de acuerdo a la antigua tradición católica, pertenecen al mismo Cristo cuando se apareció a San Pedro en el lugar actualmente deno-
} 
El origen prehispánico de este monolito es indudable debido al motivo iconográfico y a su veneración que trascendió los rigurosos ojos de la Inquisición bajo el disfraz de la Virgen de la Descención del Sunturwasi, pero que no resistió los acuciosos ojos de la Iglesia en los tiempos del Presidente Augusto B. Leguía ${ }^{25}$.

Abraham Valencia vincula esta piedra - de connotación claramente femenina ${ }^{26}$ - con una antigua deidad masculina: el dios Wiraqocha, y el sitio denominado Kiswar Kancha (hoy ocupado por el conjunto monumental de la Catedral). Pues, sumida en el sueño que le proporciona el bloque de diorita verde de la cual está hecha, está vigente aún la waka Hatun Taqe Wiraqocha, una importante pieza lítica de forma ovoide que atesoran los muros catedralicios junto con la presencia de otras divinidades andinas que guarda este histórico y monumental recinto.

Esta discutida y cuestionada pieza -de aproximadamente $0.60 \mathrm{~m}$ de alto (Fig. 19) -, en peligro de desaparición por causa del fanatismo religioso contemporáneo, de acuerdo a los investigadores corresponde a la representación abstracta del dios Wiraqocha, sobre cuyo templo está edificada actualmente la catedral cusqueña. Su forma ovoide puede relacionarse con el dibujo del cronista Juan Santa Cruz Pachacuti (Pachacuti 1993 [1613]: 208), donde aparece como el eje central de composición del "Altar Mayor" del Qorikancha, si es que esta grafía -fuertemente influenciada por la interpretación bíblica-, no representa al óculo u ojo de buey de un tímpano románico (Duviols 2002: 59-97).

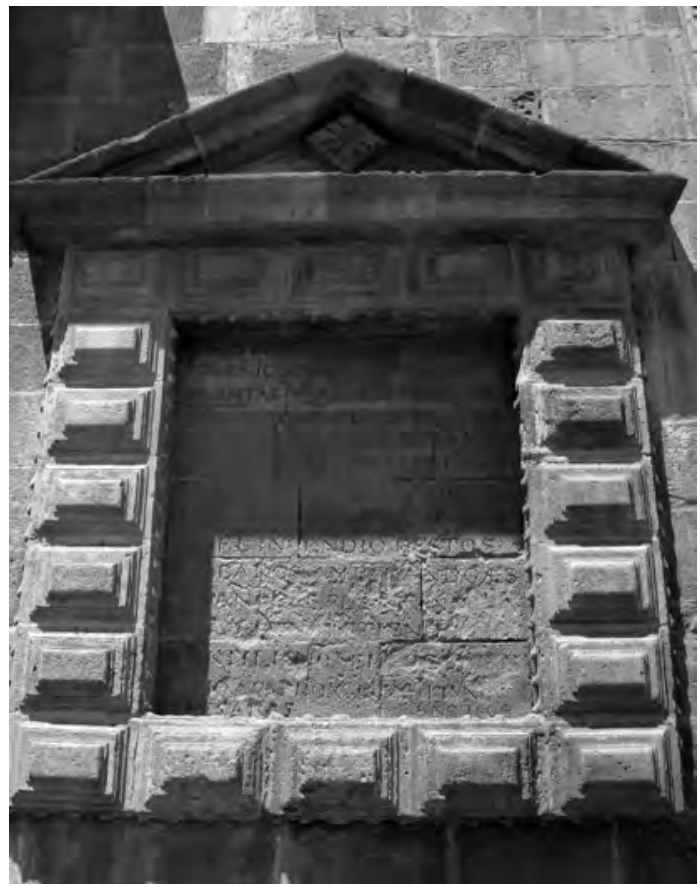

Figura 18. Inscripciones epigráficas en el Templo del Triunfo, donde se narra el descendimiento de la Virgen María al Sunturwasi, y la aparición del Apóstol Santiago.

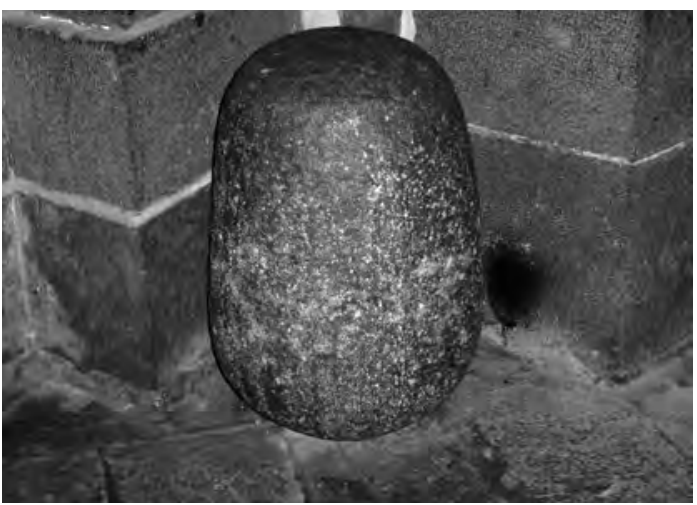

Figura 19. El monolito Hatun Taqe Wiraqocha. Catedral del Cusco.

minado Domine Quo Vadis, en la Vía Appia Antica. Igualmente, en la Catedral Primada de Toledo es posible apreciar una losa todavía de origen visigótico, donde la tradición asegura puso sus plantas la Virgen María para imponer una casulla a San lldefonso (pasaje hábilmente interpretado en uno de los lienzos del transepto de la Catedral del Cusco (Benavente 1985), obra atribuida a los pinceles de Basilio de Santa Cruz o Diego Quispe T'ito).

${ }^{25}$ La Iglesia hizo desaparecer esta valiosa muestra prehispánica más o menos por los años de 1909 a 1910, celosa al descubrir los verdaderos motivos de su veneración, casi litolátrica (Valencia Espinoza 1991: 116).

26 "Para la cultura Quechua, las Wakas siempre fueron pares, una que representa a la mujer y otro al varón, por eso dicen que son pares 'yanantin', no pueden existir uno sin el otro ya que su vínculo y su unión representan felicidad para todos los pobladores" (Valencia 1991). 


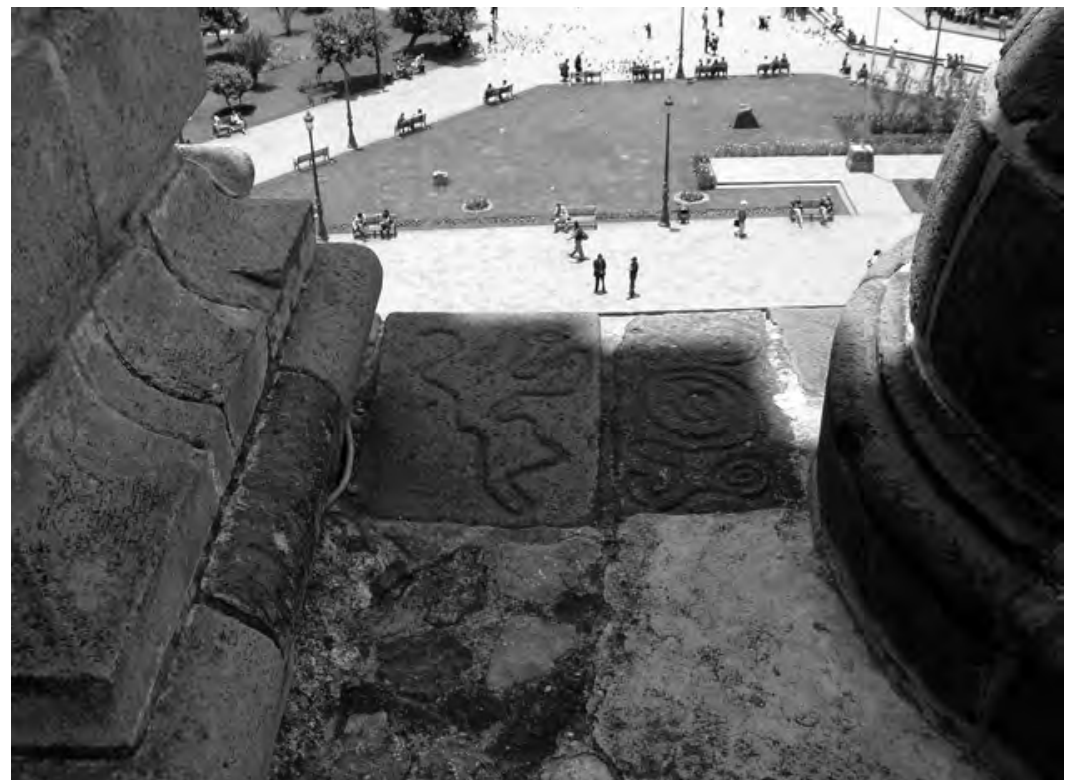

Figura 20. Petroglifos en las cornisas de la Catedral.

embutidas en muros de casonas o templos -como las presentes en las cornisas catedralicias (Fig. 20)-, o formando parte de los jambajes de portadas de antiguas casonas, levantadas durante el Virreinato reutilizando o reacoplando estas piezas en determinados sitios o lugares de la obra.

Frente a la existencia de este tipo de líticos connotados de sacralidad y tradición, en diferentes partes de la ciudad del Cusco y su área de influencia se encuentran también piedras de procedencia prehispánica con enigmáticas incisiones o grabados que las singularizan, como elementos integrantes tanto de mamposterías de muros, jambajes de puertas y portadas, pisos, pavimentos, bases de retablos o componentes de cornisamentos en Templos.

Pero, es importante mencionar que estos ejemplares no deben confundirse con las denominadas "marcas de los canteros", que aparecen signando las piezas líticas de algunas edificaciones del periodo Virreinal -como el Convento de La Merced, por citar un ejemplo-, cuya grafía expresa claramente su procedencia y significado, correspondiendo a los signos realizados por los artesanos participantes en dichas obras de edificación $^{27}$.

Entre los muchos ejemplos existentes de piedras con incisiones o petroglifos de procedencia prehispánica, destacan piezas que se exhiben

\subsubsection{Petroglifos en la arquitectura civil} cusqueña (Figs. 21 y 22)

Son importantes los vestigios que aparecen en las jambas del inmueble № 319 de la calle Wayna Pata (Barrio de San Cristóbal), del inmueble № 338 de la calle Choquechaca, y del № 544 de la Cuesta de San Blas, o en uno de los basamentos de la portada de la casa № 370 de San Andrés; así como el petroglifo que forma parte de los muros de la casa № 264 (antes 96) de la calle San Agustín. Igualmente, el petroglifo que se aprecia en la esquina de las calles Purgatorio con Córdoba del Tucumán, en la parte posterior del inmueble denominado Casa de La Torre (Plazoleta Nazarenas № 211).

Otro ejemplar se hallaba en los muros del Colegio de San Francisco de Asís - hacia la calle Nueva Baja (Zecenarro 2005a: 93)-, posiblemente relacionado con los petroglifos existentes en la nave de la cercana Capilla del antiguo Hospital de San Juan de Dios. A inicios del año 2007, esta valiosa pieza fue retirada irresponsablemente de su posición original debido a inter-

\footnotetext{
27 "Marcas de canteros en Chumbivilcas”. (Gutiérrez 1987).
} 
Figura 21. Petroglifos en la arquitectura civil del Cusco.

\begin{tabular}{|c|c|c|c|}
\hline PETROGLIFO & DIRECCIÓN & $\begin{array}{l}\text { UBICACIÓN } \\
\text { PETROGLIFOS }\end{array}$ & REGISTRO \\
\hline $\begin{array}{c}\text { Petroglifo en el } \\
\text { Inmueble Calle } \\
\text { Waynapata N³19 } \\
\text { Barrio de San } \\
\text { Cristóbal } \\
\text { (Qollqanpata) }\end{array}$ & $\begin{array}{c}\text { Calle } \\
\text { Waynapata N³19 }\end{array}$ & $\begin{array}{l}\text { Pieza de andesita } \\
\text { que conforma la jamba } \\
\text { izquierda de la puerta }\end{array}$ & \\
\hline $\begin{array}{c}\text { Petroglifo en el } \\
\text { Inmueble Calle } \\
\text { Cuesta de San Blas } \\
N^{\circ} 544 \\
\text { Barrío de San Blas } \\
\text { (Toqo Kachi) }\end{array}$ & $\begin{array}{c}\text { Calle } \\
\text { Cuesta de } \\
\text { San Blas N N } 544\end{array}$ & $\begin{array}{l}\text { Pieza de andesita } \\
\text { que conforma la jamba } \\
\text { izquierda de la puerta }\end{array}$ & \\
\hline $\begin{array}{c}\text { Petroglifo en el } \\
\text { Inmueble Calle } \\
\text { San Andrès } \\
N^{\circ} 370\end{array}$ & $\begin{array}{l}\text { Calle } \\
\text { San Andrés } \\
N^{\circ} 370\end{array}$ & $\begin{array}{l}\text { Pieza de andesita } \\
\text { ubicada al nivel del } \\
\text { umbral, conformando } \\
\text { la jamba derecha } \\
\text { del vano de ingreso }\end{array}$ & \\
\hline $\begin{array}{c}\text { Petroglifo en el } \\
\text { Inmueble Calle } \\
\text { San Agustin } \\
\text { NN}^{2} 264\end{array}$ & $\begin{array}{l}\text { Calle } \\
\begin{array}{c}\text { San Agustin } \\
\mathrm{N}^{\circ} 264\end{array} \\
\text { (antes } \mathrm{N}^{\circ} 96 \text { ) }\end{array}$ & $\begin{array}{l}\text { Pieza de andesita } \\
\text { ubicada en el } \\
\text { sobrecimiento }\end{array}$ & \\
\hline $\begin{array}{l}\text { Petroglifo en los } \\
\text { muros del Colegio } \\
\text { San Francisco } \\
\text { de Asis }\end{array}$ & $\begin{array}{c}\text { Calle } \\
\text { Nueva Baja s/n }\end{array}$ & $\begin{array}{l}\text { Pieza de andesita } \\
\text { ubicada en el } \\
\text { sobrecimiento } \\
\text { de los muros } \\
\text { del Colegio } \\
\text { (cerca a la portada) }\end{array}$ & \\
\hline $\begin{array}{l}\text { Petroglifo en el } \\
\text { inmueble } N^{\circ} 320 \text { de } \\
\text { la Calle Maruri }\end{array}$ & $\begin{array}{l}\text { Calle } \\
\text { Maruri } \mathrm{N}^{\top} 320 \\
\text { (Interior) }\end{array}$ & $\begin{array}{l}\text { Pieza de andesita, parte } \\
\text { de los mampuestos } \\
\text { del zócalo de los } \\
\text { muros que definen } \\
\text { el primer patio del } \\
\text { inmueble. }\end{array}$ & \\
\hline $\begin{array}{l}\text { Petroglifo en la calle } \\
\text { Recoleta, inmueble } \\
\text { esquina con Calle } \\
\text { Pumapaqcha N } N^{0} 290\end{array}$ & $\begin{array}{c}\text { Calle } \\
\text { Recoleta s/n }\end{array}$ & $\begin{array}{l}\text { Pieza de andesita que } \\
\text { conforma la jamba } \\
\text { izquierda del vano, muy } \\
\text { cerca a la esquina } \\
\text { con la Calle } \\
\text { Pumapaqcha }\end{array}$ & \\
\hline
\end{tabular}


Figura 22. Petroglifos en la arquitectura civil del Cusco.

\begin{tabular}{|c|c|c|c|}
\hline PETROGLIFO & DIRECCIÓN & $\begin{array}{l}\text { UBICACIÓN } \\
\text { PETROGLIFOS }\end{array}$ & REGISTRO \\
\hline $\begin{array}{c}\text { Petroglifos en el } \\
\text { Inmueble Calle } \\
\text { Hospital } N^{\circ} 792 \\
\text { Propiedad de la } \\
\text { Asociación de } \\
\text { Comerciantes } \\
\text { Ganaderos del } \\
\text { Cusco }\end{array}$ & $\begin{array}{c}\text { Calle } \\
\text { Hospital N }{ }^{\circ} 792 \\
\text { (El inmueble hace } \\
\text { esquina con la } \\
\text { Calle Oheswa) }\end{array}$ & $\begin{array}{c}\text { Caja de escaleras, } \\
\text { entrando a mano } \\
\text { derecha del zaguán. } \\
\text { Bloques líticos de } \\
\text { piedra andesita que } \\
\text { conforman los peldaños } \\
\text { de la escalera. }\end{array}$ & \\
\hline $\begin{array}{c}\text { Pieza litica en el } \\
\text { Inmueble Calle } \\
\text { Hospital N"878 } \\
\text { (posible estela } \\
\text { o wanka) } \\
\text { Propiedad de las } \\
\text { Sras. Maria y Julia } \\
\text { Montes Vera }\end{array}$ & $\begin{array}{c}\text { Calle } \\
\text { Hospital } N^{\circ} 878 \\
\text { (El inmueble tiene el } \\
\text { ingreso principal } \\
\text { por la Calle } \\
\left.\text { Umanchata } N^{\bullet} 106\right)\end{array}$ & $\begin{array}{c}\text { Pieza litica de } \\
\text { andesita que } \\
\text { conforma la parte inferior } \\
\text { de la jamba izquierda } \\
\text { de la puerta. } \\
\text { En la cara frontal de la } \\
\text { pieza se ubica el } \\
\text { petroglifo sinusoidal, y } \\
\text { en la misma jamba } \\
\text { aparece una escotadura } \\
\text { a manera de inglete, } \\
\text { junto con lineas } \\
\text { sinusoidales. }\end{array}$ & \\
\hline $\begin{array}{l}\text { Petroglifo en el } \\
\text { Colegio Nacional } \\
\text { de Ciencias }\end{array}$ & $\begin{array}{c}\text { Calle } \\
\text { Santa Clara s/n }\end{array}$ & $\begin{array}{l}\text { Pieza litica de caliza } \\
\text { calcárea, perteneciente } \\
\text { al muro prehispánico } \\
\text { llamado antiguamente } \\
\text { Chaqnapata o Andén } \\
\text { de San Buenaventura. } \\
\text { Este muro es parte } \\
\text { del camino Inka hacia la } \\
\text { región del Kontisuyo. }\end{array}$ & \\
\hline $\begin{array}{l}\text { Petroglifo de } \\
\text { LIRKAY } \\
\text { (San Jerónimo) }\end{array}$ & $\begin{array}{l}\text { Actualmente } \\
\text { conservado en el } \\
\text { Museo Inka } \\
\text { (Palacio del } \\
\text { Almirante) }\end{array}$ & $\begin{array}{l}\text { Pieza litica de piedra } \\
\text { arenisca. } \\
\text { Bloque exento. } \\
\text { Ubicación original: } \\
\text { Fundo LIRKAY, } \\
\text { Prop. Familia } \\
\text { Somocurcio. } \\
\text { Distrito de San } \\
\text { Jerónimo. }\end{array}$ & \\
\hline $\begin{array}{c}\text { Petroglifo en el } \\
\text { Inmueble calle } \\
\text { Choquechaka } N^{\circ} 338 \\
\text { Casa Núñez del Prado }\end{array}$ & $\begin{array}{c}\text { Calle } \\
\text { Choquechaka } \\
N^{\circ} 338\end{array}$ & $\begin{array}{l}\text { Piezas líticas de piedra } \\
\text { andesita, que conforman } \\
\text { parte del umbral de } \\
\text { la portada de acceso } \\
\text { al inmueble. } \\
\text { La Casa Núñez del Prado } \\
\text { está declarada } \\
\text { Monumento de la Nación } \\
\text { R.S.N.2900-72-ED } \\
28 \text { dic.1972 }\end{array}$ & \\
\hline
\end{tabular}


venciones ejecutadas en esta parte del Convento, sin el seguimiento o supervisión correspondiente de las autoridades encargadas.

Igualmente, se pueden observar estas piezas líticas dentro de inmuebles, como en las escaleras de la casa № 792 de la Calle Hospital, en el inmueble № 320 de la calle Maruri y al interior de la casona № 601 de la Cuesta de Santa Ana; así como en el patio de la Casa de los Marqueses de Casa Xara y Casa Palma, en la Plaza San Francisco № 337, espacio lamentablemente disturbado hace poco por la construcción de un Centro Educativo Estatal.

Un petroglifo significativo - a manera de una posible estela-, se encuentra en una de las jambas de la casa № 106 de la Calle Umanch'ata, como parte de los líticos que definen su puerta de ingreso por la Calle Hospital (Calle Hospital № 878) (Teófilo Benavente, comunicación personal); ubicado a pocos metros del hoy malogrado Puente de La Almudena. Posiblemente esté relacionado con el antiguo Camino prehispánico al Kontisuyo y con la misma presencia y significado ritual del puente, que originalmente permitía salvar la quebrada del río Ch'unchulmayo (Zecenarro-Quispe 2003). Igualmente, en este mismo inmueble, la puerta signada como Calle Hospital № 886, presenta rasgos muy tenues de un petroglifo de forma espiral, apreciable en la pieza inferior que conforma la jamba izquierda del vano.

Vinculado también con otro importante camino prehispánico -el que conducía al Qollasuyo-, el inmueble № 290 de la calle Pumapaqcha, esquina con la Calle Recoleta, ostenta en la jamba de su puerta que sale a esta última calle, una piedra andesita con glifos enigmáticos de formas espiraloides, diseños que posiblemente tengan algún nexo con la particularidad de la calle donde hoy están -antiguamente un sistema de andenerías por las cuales pasaba el trazo del camino -. En septiembre y marzo, fechas de los equinoccios, el eje de esta vía - cual gigan- tesco geoglifo, como lo son las calles de la antigua llaqta del Qosqo -, es paralelo a los rayos solares al amanecer y al atardecer (Zecenarro 1996; 2001).

Otra significativa expresión lítica se aprecia en el interior del inmueble Avenida Qollasuyo № 515, caserío que correspondió a la antigua Casa de Hacienda Qhari Grande. Esta en al ángulo occidental de la galería norte del patio, el podio que soporta a los arcos ostenta una pieza lítica con un petroglifo de forma espiraloide, denotando la importancia y antigüedad a esta casa y su relación con antiguos santuarios andinos vinculados con el topónimo Qhari (Cobo 1956), elemento que apoya indiscutiblemente para la conservación y puesta en valor de este inmueble, amenazado con demolerse a consecuencia del proceso de densificación urbana de la zona (OTCHC 2006).

\subsubsection{Petroglifos en la arquitectura religiosa} (Figs. 23, 24 y 25)

Un valioso petroglifo se encuentra en el coronamiento del imafronte del Templo de San Sebastián, exactamente tras del pedestal que remata el ático. Este ejemplar, de forma espiraloide cuya línea exterior se bifurca, posiblemente sea el recuerdo de la explanada ceremonial denominada Qollqapanpa (Colcabamba), sitio muy vinculado a los hermanos Ayar (Zecenarro 1996; 2001a; 2002) (Fig. 26).

Resaltan también por lo enigmático las diferentes piedras con incisiones que conforman el atrio del Templo de San Jerónimo (Figs. 13, 14 y 15), así como el pedestal escalonado sobre el cual se encumbra su cruz lítica, posible rememoración de la chakana, o de las estructuras piramidales prehispánicas sobre las cuales se "levantaba" o se "ponía" el Sol (Figs. 9 y 32).

Del mismo modo, son importantes los petroglifos que aparecen en los muros del zócalo del Templo de San Cristóbal (uno de ellos en el pavi- 
Figura 23. Petroglifos en la arquitectura religiosa del Cusco.

\begin{tabular}{|c|c|c|c|}
\hline PETROGLIFO & DIRECCIÓN & $\begin{array}{c}\text { UBICACIÓN } \\
\text { PETROGLIFOS }\end{array}$ \\
$\begin{array}{c}\text { Petroglifo en el } \\
\text { Templo de } \\
\text { San Sebastián }\end{array}$ & $\begin{array}{c}\text { Templo parroquial } \\
\text { de San Sebastián, } \\
\text { levantado sobre } \\
\text { la antigua } \\
\text { explanada de } \\
\text { Qollqapanpa } \\
\text { (Colcabamba) }\end{array}$ & $\begin{array}{c}\text { Piedra andesita, en } \\
\text { el ático del } \\
\text { imafronte. } \\
\text { Pedestal de la cruz } \\
\text { litica que remata } \\
\text { a la portada } \\
\text { retablo. }\end{array}$ \\
$\begin{array}{c}\text { Petroglifo en el } \\
\text { Templo de } \\
\text { San Cristóbal }\end{array}$ & $\begin{array}{c}\text { Templo parroquial } \\
\text { de San Cristóbal, } \\
\text { levantado sobre } \\
\text { el antiguo } \\
\text { sector de } \\
\text { Qollqanpata } \\
\text { (Colcampata) }\end{array}$ & $\begin{array}{c}\text { Piedra andesita } \\
\text { que conforma parte } \\
\text { del zócalo del muro } \\
\text { de la Epistola, hacia } \\
\text { el exterior, entre la } \\
\text { torre y la portada del } \\
\text { Templo. }\end{array}$ \\
\hline $\begin{array}{c}\text { Petroglifo en el } \\
\text { Templo de } \\
\text { San Blas }\end{array}$ & $\begin{array}{c}\text { Templo parroquial } \\
\text { de San Blas, } \\
\text { levantado sobre } \\
\text { el antiguo } \\
\text { sector de } \\
\text { Toqo Kachi }\end{array}$ & $\begin{array}{c}\text { Piedra andesita } \\
\text { que conforma }\end{array}$ \\
\hline $\begin{array}{c}\text { la mamposteria de la } \\
\text { espadaña del Templo. }\end{array}$
\end{tabular}

mento, cerca al umbral de la puerta de ingreso a la nave, situada a un costado de la torre); el que se encuentra en la base de la espadaña del Templo parroquial de San Blas, y aquella pieza que aparece en el muro del lado de la Epístola de la Basílica Menor de La Merced. En este último recinto, destacan los petroglifos que exornan algunos antepechos de los claustros, así como uno que se encuentra en la única torre.

El recinto catedralicio (Fig. 27) no queda exento de poseer estos valiosos testimonios; así, el testero de la Catedral exhibe una singular muestra ubicada en la peana que sirve de base al primitivo retablo mayor, vecino al retablo de la Santísima Trinidad. Igualmente, tres piedras que conforman las cornisas del sector del campanario del lado de la Epístola, ostentan incisiones enigmáticas cuya presencia se enseñorea aún sobre la antigua explanada Awkaypata, hoy Plaza de Armas (Fig. 20).

\subsubsection{La Estela Aqllawasi (Fig. 28)}

Pero, la estela guardada en el Monasterio de Santa Catalina de Siena (Monasterio de Nuestra Señora de los Remedios), constituye una de las piezas más interesantes, valiosas y significativas. Este monolito -de $2.00 \mathrm{~m}$ de alto, $0.20 \mathrm{~m}$ de ancho y $0.14 \mathrm{~m}$ de espesor (Fig. 29)-, ostenta una serie de glifos o incisiones que por sus formas y diseño parecen caracteres semitas u orientales, colocados en forma ordenada y vertical sobre una de sus caras frontales. Posiblemente fue una piedra wanka, que se hincaba empinada sobre algún terraplén sagrado -a manera de chaqrayoq o entidad protectora de los cultivos -, dentro de los múltiples patios o plataformas que componían el recinto sagrado del Aqllawasi, sitio correspondiente a su hallazgo.

A la posición vertical que adoptaba el monolito al ser colocado sobre una superficie plana posiblemente un campo de cultivo o plataforma ritual-, debe sumarse la disposición de las incisio- 
Figura 24. Petroglifos en la arquitectura religiosa del Cusco.

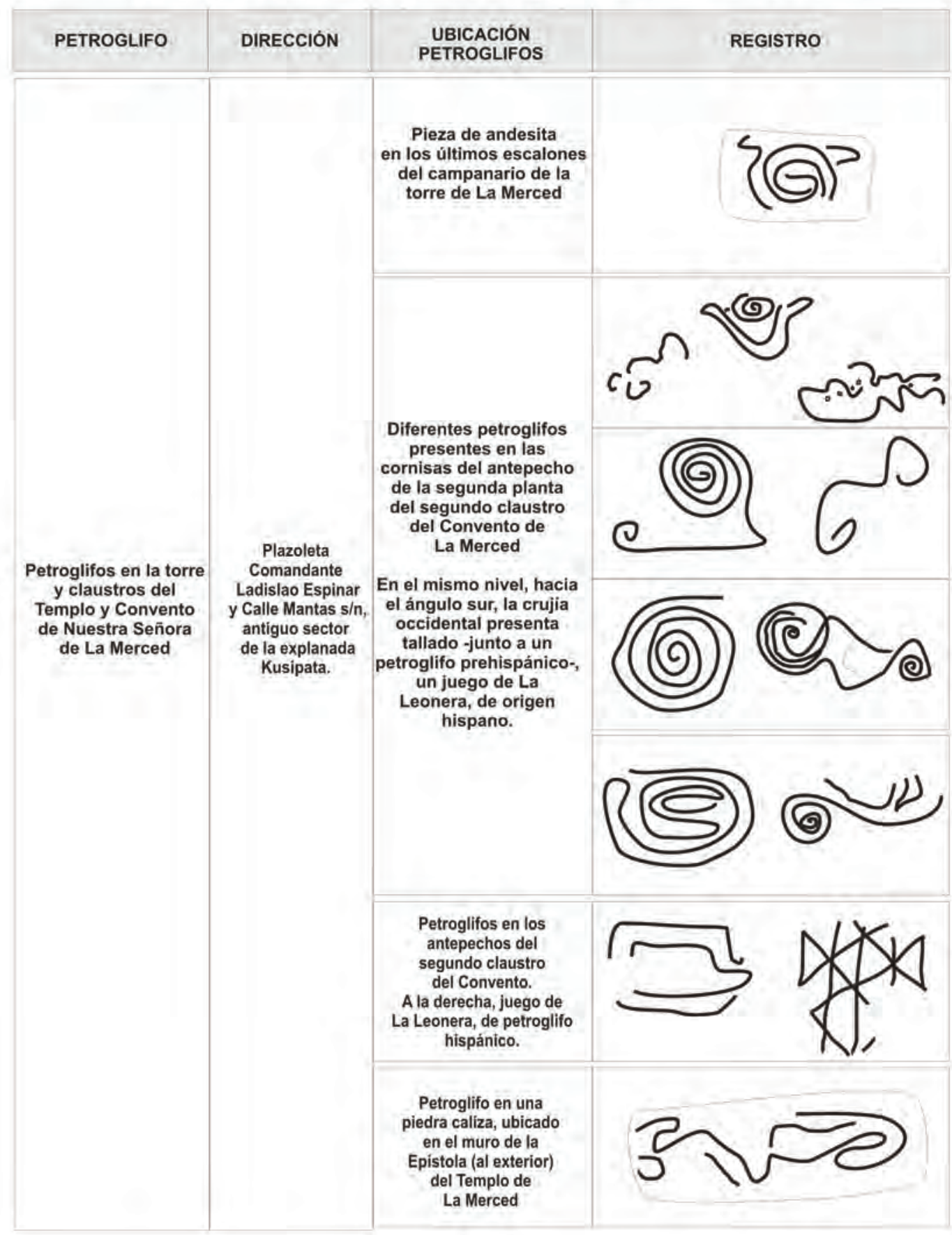


Figura 25. Petroglifos en la arquitectura religiosa del Cusco.



nes en la cara frontal de la estela, lo cual permite formar una idea de la ubicación de petroglifos y/o relieves dentro de objetos líticos sagrados similares. En muchos casos, los petroglifos existentes como parte de las expresiones arquitectónicas coloniales -templos, atrios y pedestales de cruces especialmente-, pueden corresponder a fragmentos mutilados de estelas análogas, que por su alto contenido mágico religioso fueron reutilizados en la nueva arquitectura que se introducía abruptamente en el espacio andino, para de esta manera dotarle y connotarle de significados, sentido y valor, manteniéndose así la sacralidad del sitio o lugar donde estuvo el elemento prehispánico original; una forma de persistencia de la filosofía andina en el tiempo y en el espacio frente a la implantación de nuevas estructuras ideológicas.

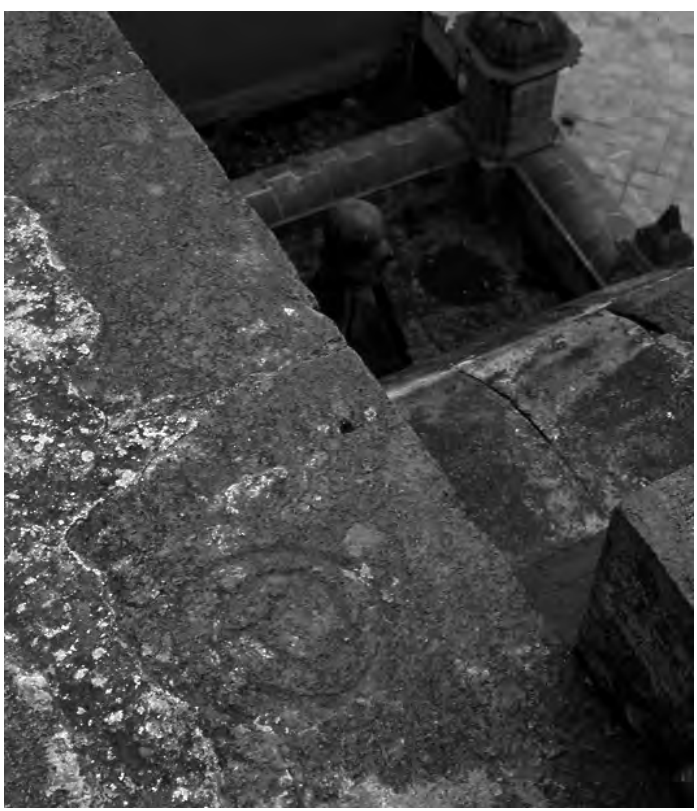

Figura 26. Petroglifo en al ático del imafronte del Templo de San Sebastián. 


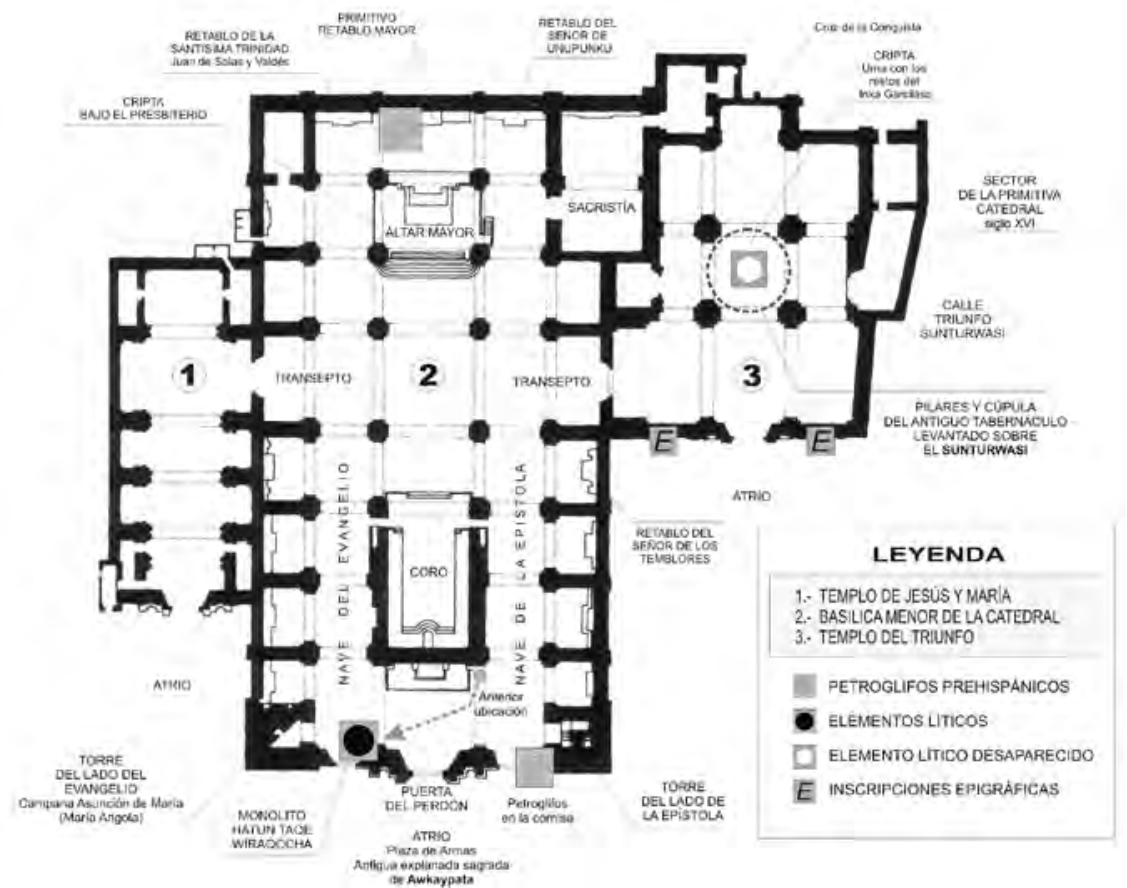

Figura 27. Ubicación de líticos y petroglifos en la Catedral del Cusco.

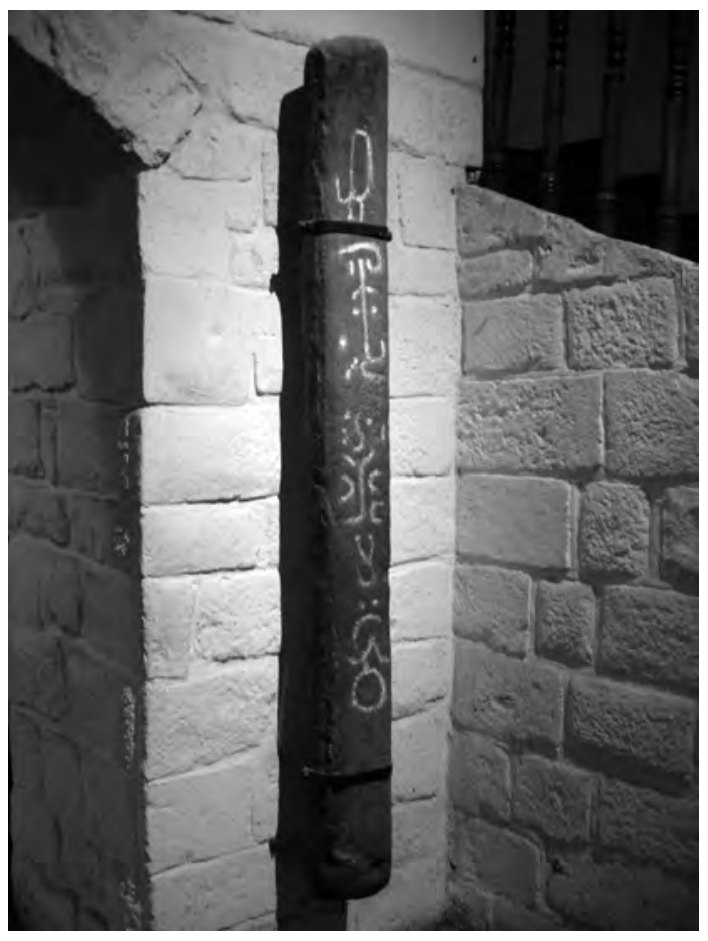

Figura 28. La Estela Aqllawasi. Monasterio de Santa Catalina.

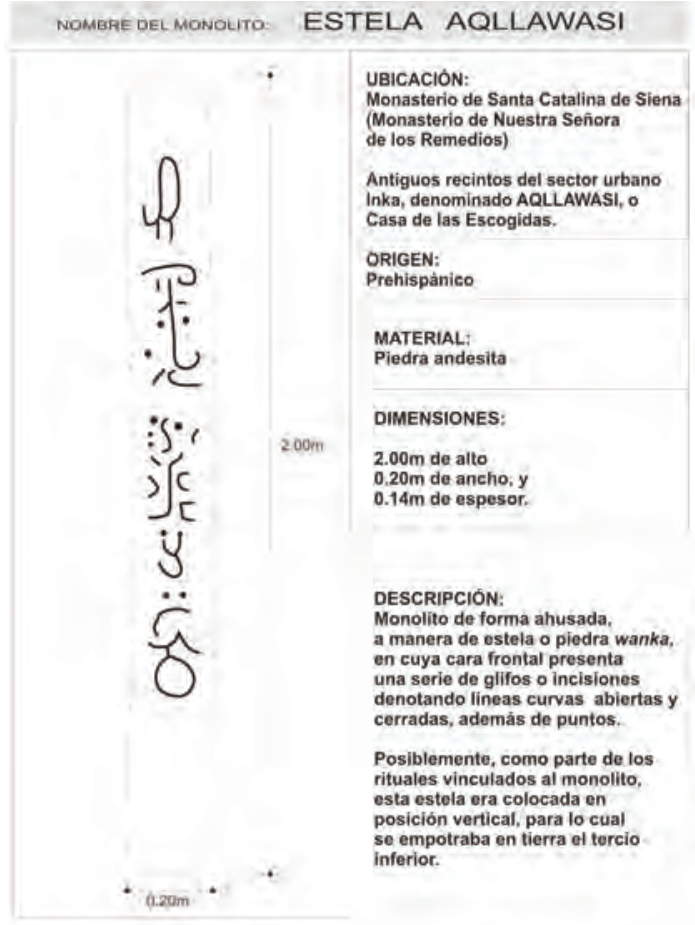

Figura 29. La Estela Aqllawasi. 
Posiblemente los enigmáticos signos que presenta la estela -como grafía o expresión físicaconnotan sus particularidades sagradas como un elemento singular asociado en este caso al Aqllawasi. Los contenidos mágico religiosos expresados en las incisiones responden a los sentimientos e ideología de la Sociedad andina que la produjo, pero lamentablemente su significado e interpretación queda por el momento en el campo hipotético, por la falta de investigaciones que permitan comprender los códigos de interpretación.

\subsection{Petroglifos en otros ámbitos de la región del Cusco}

Es importante mencionar la presencia de estas piedras con incisiones en muchos contextos geográficos de la región cusqueña, tanto vinculados con la arquitectura doméstica, como en P'isaq (recientemente destruido para dar paso a una edificación de concreto armado, 2006) (Fig. 30), como con la arquitectura virreinal religiosa.

Destacan los petroglifos que aparecen en el pedestal escalonado del Templo de Taray, en Calca, así como al interior de la nave. El mismo caso se observa en la sobrecimentación de la estructura del Templo de Kaninkunka, sobre la laguna de Urcos, aludiendo quizás a un Templo del dios Wiraqocha que existió en el lugar.

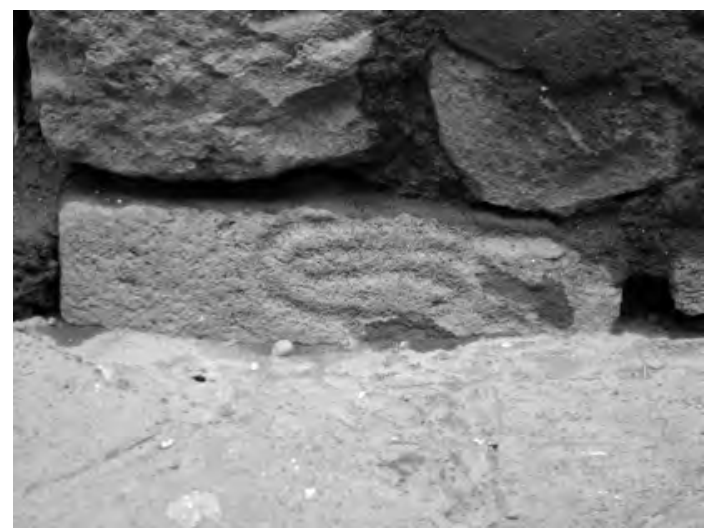

Figura 30. Petroglifo en la sobrecimentación de un inmueble. P'isaq, 2005.
En Waru (Huaro), aparecen estas losas líticas en las escalinatas del atrio; pero, donde se aprecian en mayor cantidad son en las escalinatas del atrio y en los pedestales de las cruces del cercano Templo de Andahuaylillas (Fig. 31). En el lejano Templo de Sangarará (Acomayo), aparecen los petroglifos exornando los umbrales de las portadas lateral y de pies de dicho recinto, quemado en el Siglo XVIII como parte de los sucesos de la Revolución del Inka José Gabriel Tupaq Amaru.

El Templo de Oropeza incluye estos petroglifos incrustados en la grada del presbiterio y en los bancos líticos del retablo mayor. Casos interesantes lo constituyen los pedestales escalonado de las cruces líticas de los templos de Huasac, en Paucartambo, y Zurite, en Anta, lugares donde los petroglifos se hallan mejor conservados por la misma lejanía de estos sitios.

El atrio del Templo de Chinchero es otro de los sitios muy significativos por la presencia de petroglifos, en especial en el sector del pedestal escalonado de la cruz lítica (Fig. 32), en las graderías que permiten el acceso al atrio, y sobre la superficie superior de la cornisa que corona el muro de contención prehispánico (Fig. 33), como aparecen también en Tarawasi (Limatambo, Cusco).

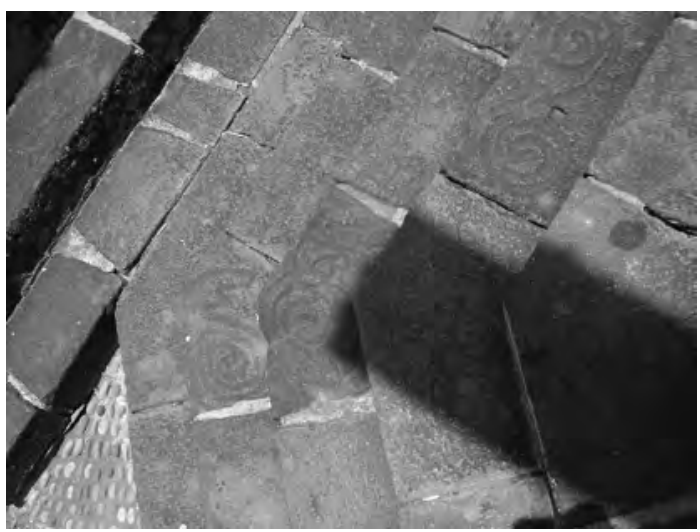

Figura 31. Piezas líticas ostentando petroglifos en el pedestal escalonado del Templo de Andahuaylillas. 


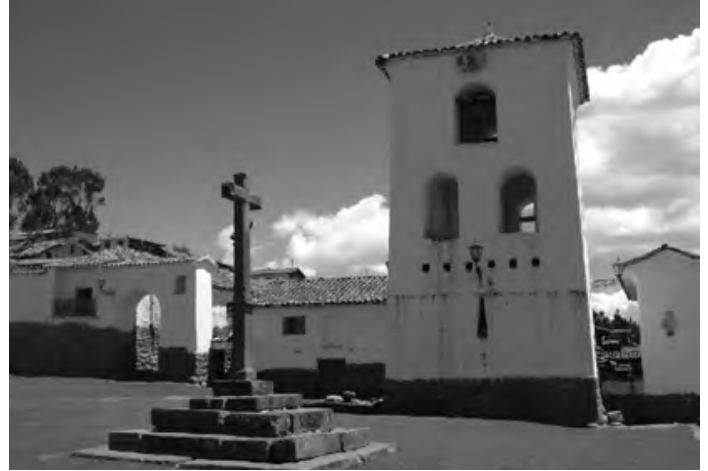

Figura 32. Cruz lítica y torre exenta de Chinchero, Cusco.

\subsection{Relieves y litoescultura}

La presencia de relieves de felinos, antropoides, aves y reptiles -incluso representaciones antropomorfas-, es una característica de las denominadas arquitecturas compactas, es decir de aquellas que aprovechan de los afloramientos rocosos para desarrollarse a través de socavones, galerías y una serie de labrados y tallas en sus caras expuestas, complementadas con los relieves indicados (Fig. 34). Un importante monumento que expresa esta forma plástica de representar los contenidos mágico-religiosos, es la famosa Piedra de Saywite, en el departamento de Apurimaq.

Generalmente en estos roquedales destaca la imagen del puma, o quizás del mítico Qoa o "Mayupuma", entidad sagrada andina, profusamente decapitada por los Extirpadores de Idolatrías, y cuya presencia escultórica ha puesto su nombre a muchos sitios y lugares del Ande. Así, son importantes los pumas de los roquedales de Puma Orqo, en Mawk'allaqta (Paruro), y de Chinchero; este último asociado a varias tradiciones que relacionan la orientación de su desaparecida cabeza con sitios donde se hallan "tapados" o fabulosos tesoros (Fig. 35).

En el Parque Arqueológico de Saqsaywaman son muchos los ejemplares de este tipo de litoesculturas, destacando los relieves existentes en Q'enqo y principalmente en Laqo, la antigua waka de Chukimarka, con sus ofidios y felinos recalcando el ingreso a una de sus cavernas y

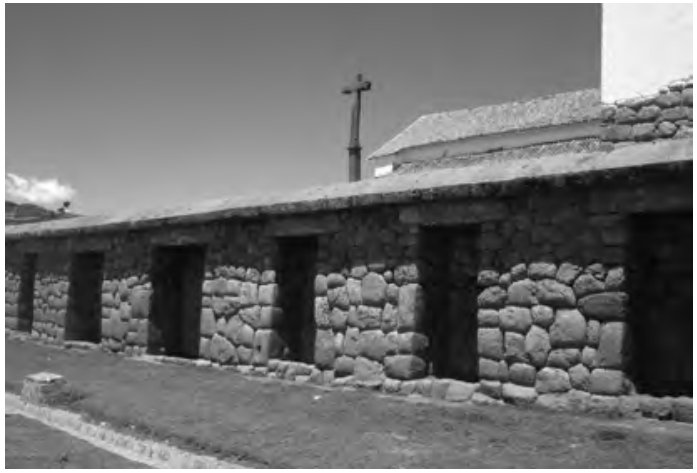

Figura 33. Muro prehispánico en la plaza de Chinchero. Cusco.

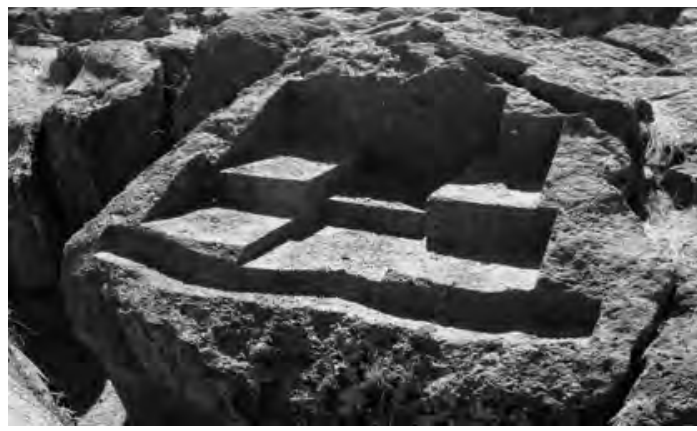

Figura 34. Piedras calizas labradas, conformando las denominadas arquitecturas compactas. Sector Chinkana Chica. Saqsaywaman, Cusco.

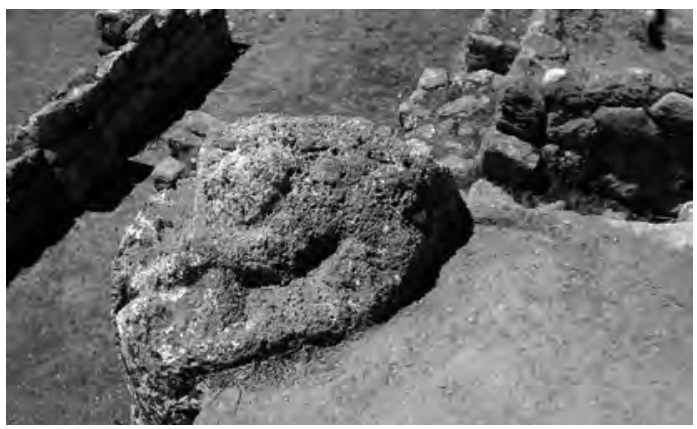

Figura 35. Puma labrado, con las patas delanteras cruzadas. Chinchero, Cusco.

exornando la cima del famoso afloramiento (Zecenarro - Quispe 2002a) (Fig. 36).

La presencia de monos es también importante. Aparecen esculpidos en altorrelieve sobre las espaldas de un posible monolito zoomorfo, en la zona de K'usilluchayoq. La connotación mágica que trasciende en la arquitectura virreinal, espe- 
cialmente del Altiplano, relaciona los monos con la arquitectura como dioses que sustentan los edificios (Gisbert 1994; Mesa - Gisbert 1966) ${ }^{28}$.

Como una variante de este tipo de elementos, se deben mencionar a las protuberancias que aparecen sobre las caras de muchos mampuestos de muros (Fig. 37). Si bien existen interpretaciones que relacionan estas molduras salientes mal denominadas ménsulas o tetones -, con clavos o dientes líticos que servían para ayudar en el montaje de las piezas durante el proceso constructivo de los paramentos ${ }^{29}$; otras teorías explican que en ciertas épocas del año y a determinadas horas del día, las sombras proyectadas arrojan formas de cabezas de pumas o cóndores, tal es el caso de los muros del sector Araqama Ayllu de Ollantaytambo (Salustio Gutiérrez Pareja, comunicación personal).

Otro elemento importante, que durante el periodo de Transición en el Cusco se va a manifestar fuertemente conjugado con representaciones heráldicas, es la presencia de felinos exornando y flanqueando portadas, a manera de cartelas. Si bien en Cusco no ha quedado ningún ejemplar de este tipo, este es el caso de la portada denominada Qoa Punku, de Wanukopanpa (Huanuco Pampa) (Barreda 1995).

Por estas consideraciones, estos elementos no pueden ser entendidos únicamente como decoración u ornamentación. Por el contrario, pertenecen a todo un sistema mágico religioso y también sirven de apoyo a las observaciones astronómicas que podían ser parte las funciones asignadas a los recintos, muros o bloques líticos donde se ubican.

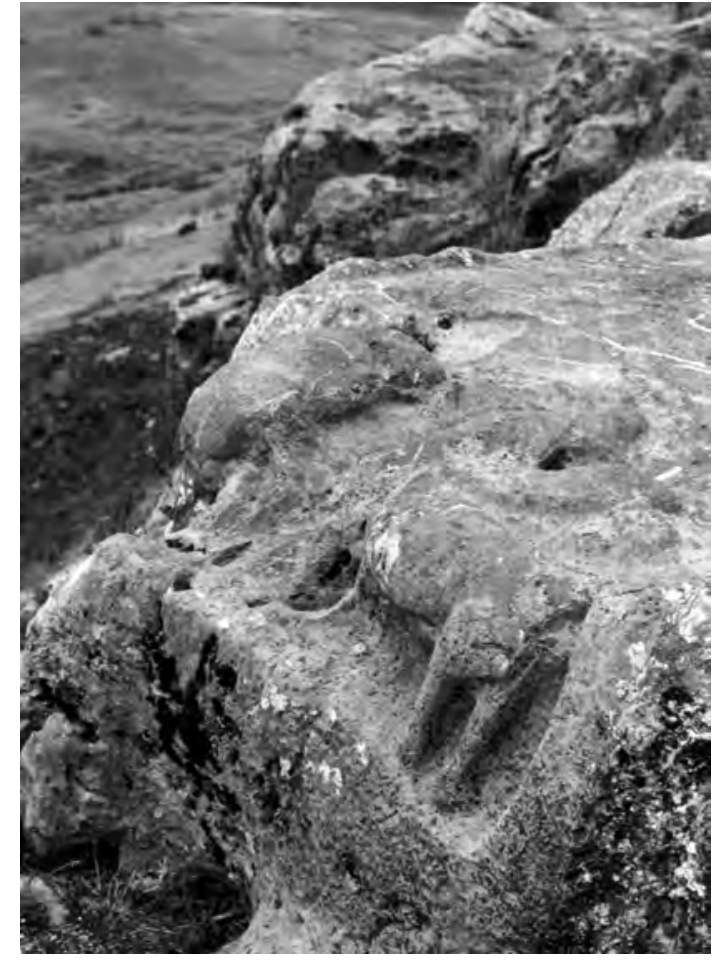

Figura 36. Pumas labrados en la cima del afloramiento calizo de Laqo, Cusco.

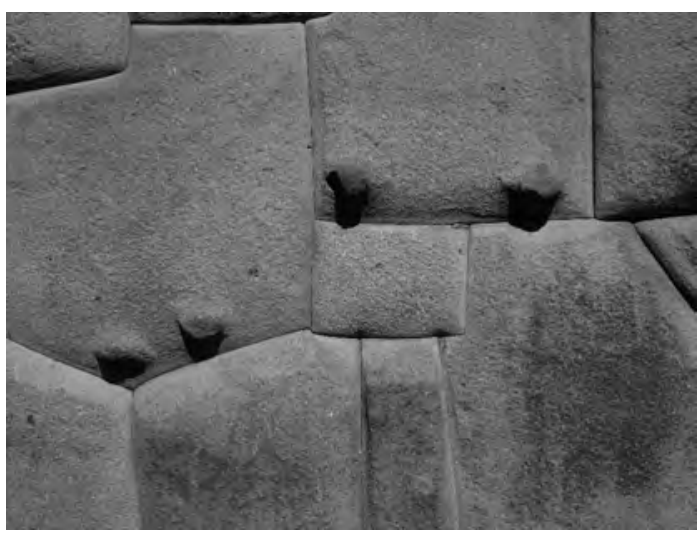

Figura 37. Aparejos del usnu de Hatunrumiyoq. Pasaje Inka Roqa. Cusco.

\footnotetext{
${ }^{28}$ En Huarochirí, los padres Dávila y Cuevas indicaron: "En las ventanas de una Iglesia echamos de ver muy acaso, que estaban dos micos de madera, y sospechando lo que era, se averiguó que los reverenciaban, porque sustentasen el edificio, y tenían sobre ello una larga fábula". José de Arriaga Extirpación de la idolatría en el Perú. Cita tomada de Contribuciones al estudio de la arquitectura andina. José de Mesa y Teresa Gisbert.

${ }^{29}$ Como un símil o paralelo, estos elementos y su posible función constructiva son característicos de la arquitectura egipcia, y pueden observarse en el complejo funerario del faraón Kefrén (IV Dinastía, 2575-2465 a.C.): el Templo del
} 


\subsection{Relieves en la arquitectura cusqueña de transición}

El uso de estos relieves y entalladuras debió haber sido frecuente como expresión mágico religiosa, puesto que se mantuvo como rezago en la arquitectura cusqueña de Transición; es decir, en aquella desarrollada en las primeras décadas del Siglo XVI, cuando se edifican obras bajo los cánones europeos, pero utilizando la tecnología constructiva tradicional Inka.

En este punto es importante mencionar una olvidada lápida con la representación de una sirena medieval (ser mitad cuerpo de mujer y mitad cuerpo de pez, muy diferente a la sirena griega) (Fig. 38), embutida en los muros de contención de Qollqanpata (Collcampata) -antigua parroquia de San Cristóbal-, y que se encuentra asociada a un manantial muy venerado por los Inkas.

Por los pechos de la sirena brotaba el agua del manante sagrado, elemento connotado como uno de los adoratorios prehispánicos perteneciente al cuadrante de Chinchaysuyo: la waka - manante Qori Oqllo [Ch. 4:3] (Zecenarro 2001a:147). Esta entidad sagrada prehispánica de género femenino-, fue hábilmente vinculada con la iconografía occidental de la mujer pez, y estuvo muy ligada a la presencia de un nicho arquitectónico por el cual aforaba el manantial indicado.

Relieves representando seres de la cosmovisión andina, aparecen apoyando o confundiéndose con las piezas mitológicas y heráldicas traídas por los hispanos para connotar sus orígenes e ilustres apellidos. Así, se tienen expresiones escultóricas que decoran tanto frisos como dinteles de las nuevas edificaciones construidas durante este importante período (Fig. 39).

Los ejemplos más significativos en la ciudad del Cusco corresponden a un friso decorado con

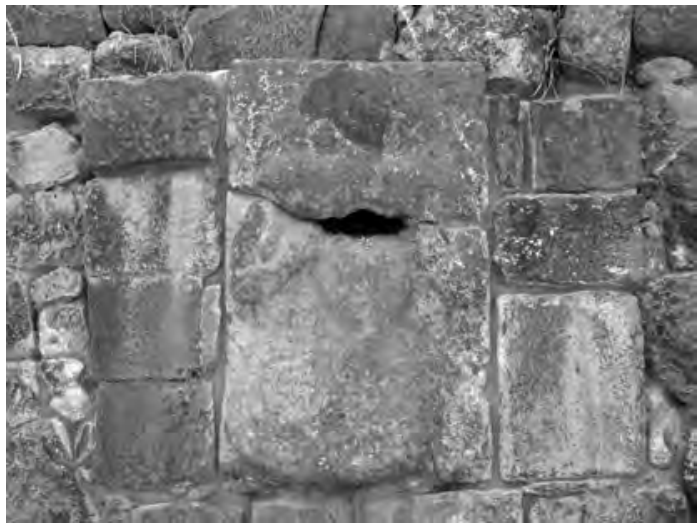

figura 38. Sirena labrada a manera de fuente, posiblemente vinculada con la waka Qori Oqllo.

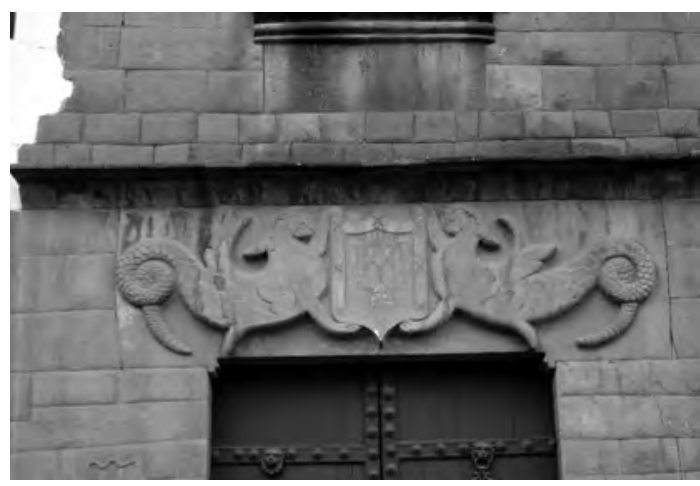

Figura 39. Escudo heráldico de la Casa de Las Sierpes. Plazoleta de Las Nazarenas.

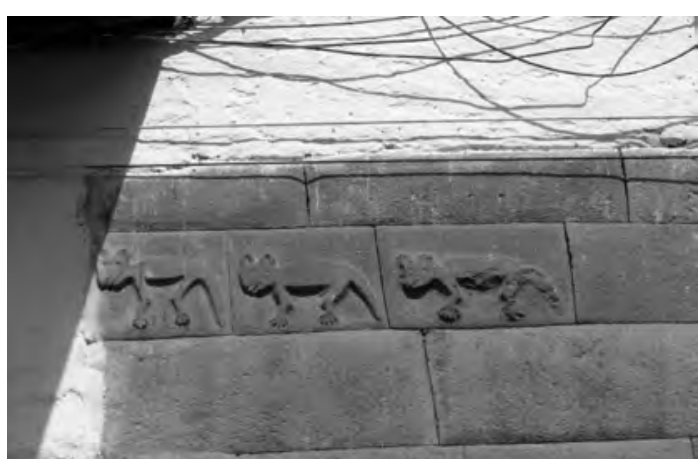

Figura 40. Cuadrúpedos labrados a manera de friso. Calle Santa Teresa.

cuadrúpedos en bajorrelieve, en la casa № 385 de la calle Santa Teresa (Fig. 40), así como a una

Valle o de la Esfinge, en Gizah (El Cairo); igualmente, aparecen en los mampuestos de mármol de muchos edificios de la Acrópolis de Atenas, llamando la atención el sector de los Propíleos o Propylaea (437 -431 a.C.). 


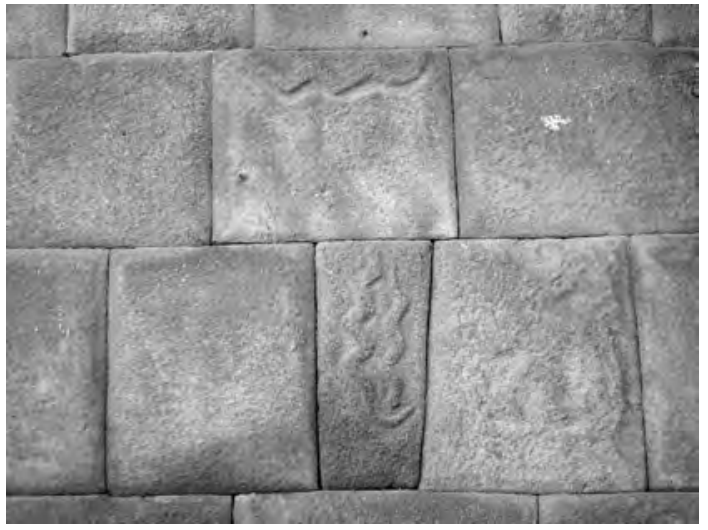

Figura 41. Serpientes en los paramentos de la Casa de Las Sierpes. Plazoleta de Las Nazarenas.

gran serie de serpientes de diversas formas y tamaños, que ornamentan ciertas piedras componentes de los aparejos del Periodo de Transición, destacando aquí las de la calle Siete Culebras, en la antigua casa de Mancio Sierra de Leguísamo o Beaterio de Las Nazarenas (Fig. 41), y las de la Casa Cartagena (calle Pumacurco № 336), entre otros.

Los elementos más importantes son los dinteles pertenecientes a las denominadas Portadas de Transición. Estos grandes monolitos, dispuestos con su cara mayor paralela al plano de la fachada, es decir teniendo el canto como sofito del vano -a la inversa que en las portadas Inkas precedentes-, presentan esculpidos sobre estas caras frontales ofidios y cuadrúpedos ${ }^{30}$ a manera de figuras o cargas de blasones heráldicos, posiblemente connotando la prosapia y genealogía real o nobiliaria de sus ilustres ocupantes, los Inkas Cristianos.

Destacan como ejemplos la portada de la calle Loreto o Intik'ijllu, en el sector correspondiente al antiguo Amaru Kancha; y la magnífica

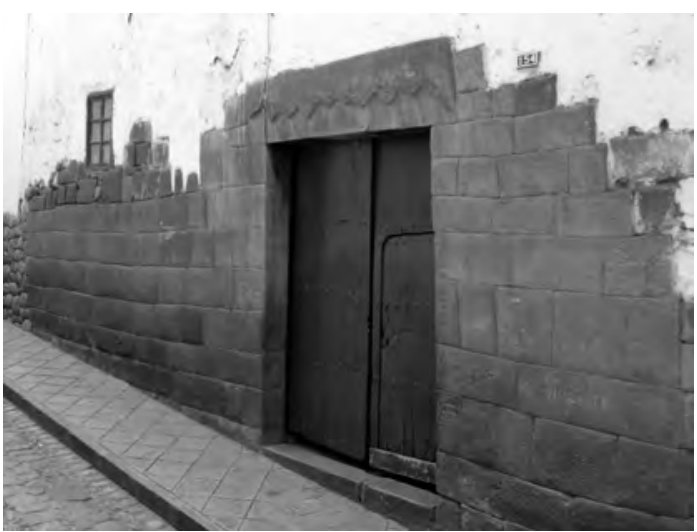

Figura 42. Portada del inmueble № 154 de la Calle Ataocalle.

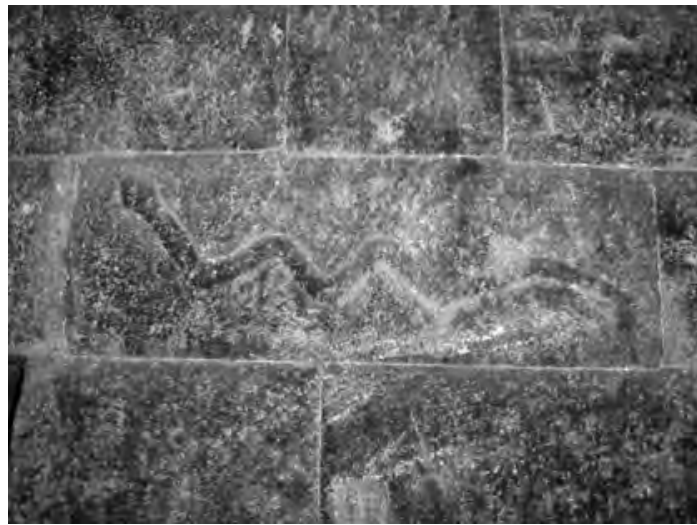

Figura 43. Serpiente labrada en el zaguán del inmueble № 154 de la Calle Ataocalle.

portada del inmueble № 154 que perteneciera a Manqo Inka -donde presumiblemente nació el Inka Ataowallpa-, en la cuesta denominada Ataocalle (Fig. 42), cuyo dintel monolítico presenta dos serpientes o AMARUS, símbolos sagrados de los Andes, que posiblemente continuaron representando todo su contenido y poder telúrico bajo la forma que el disfraz heráldico les proporcionaba (Fig. 43).

\footnotetext{
${ }^{30}$ Aquí merece indicarse la presencia de dos cuadrúpedos esculpidos en el dintel monolítico de una portada de transición, ubicada en la Plaza principal del cercano pueblo de Andahuaylillas, Quispicanchis - Cusco.
} 


\section{Bibliografía}

Academia Mayor de la Lengua Quechua

1995 Diccionario quechua-españolquechua/qheswa-español-queswa simi taqe. Municipalidad del Qosqo, Cusco.

Acosta, José de

1954 Historia natural y moral de las Indias [1590]. En Obras del Padre José de Acosta de la Compañía de Jesús. ed. P. Francisco Mateos. Biblioteca de Autores Españoles. Vol. 73. Ediciones Atlas, Madrid.

Anónimo

1586 Vocabulario y phrasis en la lengua general de los indios del Perú, llamada Quichua y en la lengua española. En los Reyes, por Antonio Ricardo. Año de MDLXXXVI. Quinta edición publicada con un prólogo y notas de Guillermo Escóbar Risco. Edición del Instituto de Historia de la Facultad de Letras. Universidad Nacional Mayor de San Marcos, Lima 1951.

Arriaga, Pablo Joseph de

1999 La extirpación de la idolatría en el Piru (1621). Estudio preliminar y notas de Henrique Urbano. Centro de Estudios Regionales Andinos "Bartolomé de Las Casas", Cusco.

Barreda Murillo, Luis

1994 Cuzco, Historia y Arqueología Preinka. Instituto de Arqueología Andina Machupiqchu, Cuzco.

1995 Wanuku Pampa Inka Llaqta. Obra de los Cuzqueños. En Revista Andes. Facultad de Ciencias Sociales de la Universidad Nacional de San Antonio Abad. №1. págs. 199-129

Bauer, Brian S.

1992 Avances en arqueología andina, Centro de Estudios Regionales Andinos Bartolomé de las Casas, Cusco.
1998 The Sacred Landscape of the Inca: The Cuzco Ceque System, University of Texas Press, Austin.

2000 El Espacio Sagrado de los Incas. El Sistema de Ceques del Cuzco, Centro de Estudios Regionales Andinos Bartolomé de las Casas, Cusco.

Benavente Velarde Teófilo

1985 Historia del Arte Cusqueño. Pintores cusqueños de la Colonia, Municipalidad del Cusco.

2006 Historia del Arte Cusqueño. Imaginería o Escultura Religiosa Cusqueña de los Siglos XVI, XVII y XVIII. Publicación Familia Benavente Gutiérrez, Lima.

(Obra inédita) Tumbas Ilustres en Templos cusquenos.

Betanzos, Juan de

1968 Suma y narración de los Incas. En Crónicas peruanas de interés indígena. Editorial Atlas. Biblioteca de Autores Españoles № 209, Madrid.

1999 Suma y narración de los Incas. Prólogo, trascripción y notas por María del Carmen Martín Rubio. Estudios preliminares de Horacio Villanueva Urteaga, Demetrio Ramos y María del Carmen martín Rubio. Universidad nacional de San Antonio Abad del Cusco, Cusco.

Blanco, José María

1974 Diario del Viaje del Presidente Orbegoso al Sur del Perú.Edición, Prólogo y Notas de Félix Denegri Luna. Universidad Católica, Lima

Breitinger, Roland

1976 Kalenderbestimmung der Inka.Ve r l a g Wilhelm Kempter KG, Ulm

Calancha, Antonio de la

1953 Coronica moralizada del orden de San Avgustin en el Perv, con sucesos egenplares en esta Monarquia [1639] Pedro Lacavallería, Barcelona. 
Castillo Benites, Daniel S.

2006 Arte Rupestre en la cuenca del Río Chicama. Editor Luis Valle Álvarez. Ediciones Sian. Primera edición, Trujillo.

Cerrón - Palomino, Rodolfo

2004 El Aimara como lengua oficial de los Incas. En Boletín de Arqueología de la Pontificia Universidad Católica del Perú. PUCP № 8, Lima. págs. 9-21.

Cobo, Bernabé

1956 Historia del Nuevo Mundo.Publicaciones Pardo-Galimberti, Cuzco.

1980 Relación de las guacas del Cuzco [1653].Ñawpa Pacha 17 (1979): 2-80

2000 Relación de las guacas del Cuzco. Historia del Nuevo Mundo [1653]. Libro 13/f.223 vta./trascripción de John. H. Rowe. En El Espacio Sagrado de los Incas. El Sistema de Ceques del Cuzco, Brian S. Bauer. Centro de Estudios Regionales Andinos Bartolomé de las Casas, Cusco.

Cusihuamán, Antonio

1976 Diccionario Quechua Cuzco-Collao Ministerio de Educción. Instituto de Estudios peruanos. 1ra. Edición, Lima.

Del Solar M., César y Hostnig, Rainer

2006 Litograbados indígenas en la Arquitectura colonial del Departamento del Cusco, Perú . En Rupestreweb, http:// rupestreweb2.tripod.com/litograbados1.html

Duviols, Pierre

2002 Mestizaje cultural en dos cronistas del incipiente barroco peruano: Santa Cruz Pachacuti y Guaman Poma de Ayala. En El Barroco Peruano. Banco de Crédito del Perú.

Farfán, José M.b.

1971 Glosario de voces indígenas. En Historia del Perú Antiguo. Luis E. Valcárcel. Ed. Juan Mejía Baca. Tomo VI. Págs. 555617. Editorial Universitaria, Lima.

Garcilaso Inca de la Vega

1960 Los Comentarios Reales de los Incas. Primera Parte. Ediciones de la Universidad Nacional del Cuzco.
Gisbert, Teresa

1994 Iconografía y Mitos Indígeneas en el Arte. Segunda Edición, La Paz.

Guaman Poma De Ayala, F.

1956 El primer nueua coronica i buen gobierno [1616], Historia Prehispánica del Perú. Primera parte. Editorial Cultura, Lima.

Gutiérrez, Ramón

1987 Arquitectura Virreynal en Cuzco y su Región. Editorial Universitaria UNSAAC, Cusco

Gutierrez Pareja, Salustio

1980 Ciudades Ocultas del Cusco Milenario. Editorial Andina, Cusco.

1984 CaminosalAntisuyo.En Revista del Museo e Instituto de Arqueología №23. UNSAAC.

Hostnig, Rainer

2003 Arte Rupestre del Perú. Inventario Nacional Consejo Nacional de Ciencia, Tecnología e Innovación Tecnológica. CONCYTEC

Kauffmann Doig, Federico

1983 Manual de Arqueología Peruana Octava edición. Ediciones PEISA, Lima.

Mesa, José de y Gisbert, Teresa

1966 Contribuciones al estudio de la arquitectura andina. Academia Nacional de Ciencias de Bolivia, La Paz.

Murúa, Martín de

1946 Historia del origen y genealogía real de los reyes Incas del Perú [1590], Ed. Constantino Bayle, Instituto Santo Toribio de Mogrovejo, Madrid.

2001 Historia General del Perú. Ed. Manuel Ballesteros Gaibrois. Dastin Historia, Madrid.

Oficina Técnica del Centro Histórico Del Cusco (otchc).

2006 La Casa de Hacienda Qhari Grande Informe realizado por los arquitectos Yadira Guerra Vera y Germán Zecenarro Benavente. Equipo técnico OTCHC. Programa P>D Patrimonio para el Desarrollo AECI - Perú. Acuerdo 
Municipalidad del Cusco - Agencia Española de Cooperación Internacional. Gerencia de Desarrollo Urbano y Rural de la Municipalidad del Cusco.

Pachacuti Yamqui Salcamaygua, Joan de Santa Cruz

1993 Relación de Antiguedades deste Reyno del Piru. [1613] Institut Français D'Études Andines. CBC, Cusco.

Pardo, Luis A.

1957 Historia y Arqueología del Cuzco. UNSAAC

Pizarro, Pedro

1986 Relación del descubrimiento y conquista de los reynos del Perú. Pontificia Universidad Católica del Perú. Segunda edición, Lima.

Polo de Ondegardo, Juan

1916a De los errores y supersticiones de los indios, sacados del tratado y averiguación que hizo el Licenciado Polo [1585]. En Vol.3, Información acerca de la religión y gobierno de los Incas. Colección de Libros y Documentos Referentes a la Historia del Perú. Sanmartí. Lima.

1916b Relación de los fundamentos acerca del notable daño que resulta de no guardar a los indios sus fueros [1571]. En Vol.3, Información acerca de la religión y gobierno de los Incas. Colección de Libros y Documentos Referentes a la Historia del Perú. Sanmartí. Lima.

1917 Relación de los Adoratorios de los Indios en los Cuatro Caminos (ceques) que Salian del Cuzco. [1571]. Informaciones Acerca de la Religión y Gobierno de los Incas (2da. Parte). Colección de Libros y Documentos referentes a la Historia del Perú. Serie 1, tomo 4. Imprenta y Librería Sanmartí y Cia, Lima.

Quispe Ricalde, María Elena

2006 Lectura urbana del poblado de San Sebastián - Historia e Interpretación. Primera edición, Cusco.
Quispe Ricalde, María Elena y Zecenarro Benavente, Germán

2002a Laqo: Una waka de Antisuyo. En Revista Medio de construcción. Año XV, Edición №170, Lima, págs. 48-55.

2002b Tipón: Arquitectura Inka y culto al agua. En Revista Medio de construcción. Año XV, Edición №171. Lima. Págs. 46-52.

2003 En debate el destino del Puente de La Almudena. En Revista Medio de construcción. Año XVII, Edición №180, Lima. Págs. 44-47.

Ramos Gavilán, Alonso

1860 Historia de Copacabana y de su milagrosa imajen de la Virgen / escrito por el R.P. Fr. Alonso Ramos Gavilán; compendiada por el P. Fr. Rafael Sans; con aprobación del Illmo. Sr. Obispo, Dr.D. Mariano Fernández de Córdova. Impr. de Vapor Calle de la Aduana N 36. La Paz.

1988 Historia del Santuario de Nuestra Señora de Copacabana. [1621]. Ed. Ignacio Prado Pastor, Lima.

Rostworowski de Diez Canseco, Marçia

1988a Historia del Tahuantinsuyo. IEP Instituto de Estudios Peruanos, Lima.

1988b Estructuras Andinas del Poder. Ideología religiosa y política. IEP Instituto de Estudios Peruanos, Lima.

Sarmiento de Gamboa, Pedro

1942 Historia de los Incas. EMECE Editores, S.A. - Buenos Aires.

Toledo, Francisco de

1940 Informaciones que mando levantar el virrey Toledo sobre los incas [1570 1572], en: R. Levillier (ed.), Don Francisco de Toledo, supremo organizador del Perú: su vida, su obra, tomo II, sus informaciones sobre los incas (1570. 1572) 1-204, Colección de Publicaciones Históricas de la Biblioteca del Congreso Argentino, Buenos Aires.

Valcárcel, Luis. E.

1971 Historia del Perú Antiguo. Ed. Juan Mejía Baca. Editorial Universitaria, Lima. 
Valencia Espinoza, Abraham

1991 Taytacha Temblores. Patrón Jurado del Cuzco. UNSAAC. Cusco

Zecenarro Benavente, Germán

1996 Arquitectura arqueológica en la Quebrada de Thanpumach'ay - Reconstrucción hipotética al siglo XVI. Tesis de grado. Facultad de Arquitectura y Artes Plásticas. UNSAAC.

1999 El Sistema Suqanqa de Choqekiraw Pukyo. En Revista Arkinka, Año 4, № 48, Lima. Págs. 88-99.

2001a Arquitectura Arqueológica en la Quebrada de Thanpumach'ay. Primer a edición. Municipalidad Provincial del Cusco.

2001b Inkilltambo. En revista Arkinka, Año 6, № 68, Lima. Págs. 86-96.

2002 Apus Tutelares y Asentamientos del Cusco Preinka. En Revista Arkinka, Año 7, № 82, Lima. Págs. 88-96.

2003a Tambomachay y los Adoratorios andinos del Primer seqe al Antisuyo. En revista Arkinka, Año 8, № 91, Lima. Págs. 8699.

2003b Apus Tutelares y Asentamientos del Cusco Preinka. En Boletín de Arqueología de la Pontificia Universidad Católica del Perú. PUCP № 7, Lima. Págs. 387-405.

2004a Saywas y Suqanqas. Usnus y Asientos del Sol. Instrumentos de medición astronómica prehispánica. En revista Arkinka, Año 9, № 106, Lima. Págs. 86-98.

2004b Piedras sagradas del Cusco milenario. Los relieves y petroglifos como expresión mágico religiosa. Documento de ponencias (CD-ROM) del I Simposio Nacional de Arte Rupestre, Cusco.

2005a Piedras sagradas del Cusco milenario. Los relieves y petroglifos como expresión mágico religiosa. En revista Arkinka, Año 10, № 110, Lima. Págs. 88-97.

2005b Las Wakas. Dioses y Santuarios del Cusco prehispánico. En Revista Waka XXI, Facultad de Arquitectura, Urbanismo y Artes de la Universidad Nacional de Ingeniería. Año 1, Edición № 2, Lima. Págs. 76-82.

2006a Nota introductoria sobre la escultura Inka. En Historia del Arte cusqueño. Imaginería o Escultura Religiosa Cusqueña de los Siglos XVI, XVII y XVIII. Teófilo Benavente Velarde. Publicación Familia Benavente Gutiérrez, Lima. Págs. XV-XXI.

2006b Las Llaqtas. Algunos alcances para el estudio de las estructuras urbanas Inkas. En revista Arkinka, Año 10, № 132, Lima. Págs. 86-95. 